Marking to

Market versus

Taking to

Market

Guillaume Plantin

Jean Tirole

SRC Discussion Paper No 51

December 2015

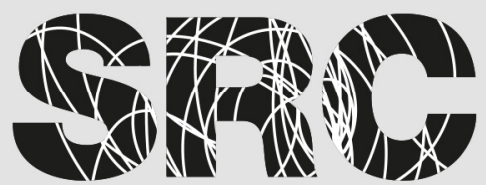




\begin{abstract}
While the debate on cost and market-value accounting has been raging for years, economists lack a framework allowing a comparison of their relative merits. This paper considers an agency model in which the measurement of an asset can be based on public market data (marking to market) and/or on the realization of its value through costly resale to an informed buyer (taking to market). At the optimal contract, noisier market data lead to cost accounting and gains trading (selling winners/keeping losers) whereas accurate data naturally favor market-value accounting. The quality of market data and the magnitude of resale costs both depend on the volume of transactions, and therefore on accounting rules. The paper studies the mutual feedback between individually optimal accounting rules and asset market liquidity. This equilibrium approach reveals a socially excessive use of market-value accounting that dries up market liquidity and reduces the informativeness of price signals.
\end{abstract}

Keywords: cost and market value accounting, agency, gains trading, equilibrium accounting rules.

JEL classification: D82, M41, M52

This paper is published as part of the Systemic Risk Centre's Discussion Paper Series. The support of the Economic and Social Research Council (ESRC) in funding the SRC is gratefully acknowledged [grant number ES/K002309/1].

Guillaume Plantin, Sciences Po and Systemic Risk Centre, London School of Economics and Political Science

Jean Tirole, TSE and IAST

Published by

Systemic Risk Centre

The London School of Economics and Political Science

Houghton Street

London WC2A 2AE

All rights reserved. No part of this publication may be reproduced, stored in a retrieval system or transmitted in any form or by any means without the prior permission in writing of the publisher nor be issued to the public or circulated in any form other than that in which it is published.

Requests for permission to reproduce any article or part of the Working Paper should be sent to the editor at the above address.

(C) Guillaume Plantin and Jean Tirole, submitted 2015 


\title{
Marking to Market versus Taking to Market*
}

\author{
Guillaume Plantin \\ Sciences Po \\ Jean Tirole \\ TSE and IAST
}

November 25, 2015

\begin{abstract}
While the debate on cost and market-value accounting has been raging for years, economists lack a framework allowing a comparison of their relative merits. This paper considers an agency model in which the measurement of an asset can be based on public market data (marking to market) and/or on the realization of its value through costly resale to an informed buyer (taking to market). At the optimal contract, noisier market data lead to cost accounting and gains trading (selling winners/keeping losers) whereas accurate data naturally favor market-value accounting. The quality of market data and the magnitude of resale costs both depend on the volume of transactions, and therefore on accounting rules. The paper studies the mutual feedback between individually optimal accounting rules and asset market liquidity. This equilibrium approach reveals a socially excessive use of market-value accounting that dries up market liquidity and reduces the informativeness of price signals.
\end{abstract}

Keywords: cost and market value accounting, agency, gains trading, equilibrium accounting rules.

JEL numbers: D82, M41, M52.

*We thank Régis Breton, Charles Calomiris, Doug Diamond, Ron Dye, Pingyang Gao, Stéphane Guibaud, Christian Leuz, Bob McDonald, Alessandro Pavan, Haresh Sapra, and Lars Stole for helpful comments. We also thank seminar participants at Banque de France, the Chicago Booth School of Business, the Systemic Risk Centre (LSE), the University of Zurich, and at conferences (CRESSE 2015, NBER Summer Institute 2015, 2015 European Economic Association meeting). Tirole gratefully acknowledges financial support from the ERC programme grant FP7/2007-2013 No. 249429 Cognition and DecisionMaking: Laws, Norms and Contracts. This research also benefited from a joint research grant Autorité des Normes Comptables-Caisse des Dépôts et Consignations to the Institut d'Economie Industrielle. 


\section{Introduction}

As professional and academic accountants have long emphasized, accounting conventions come to life when they are actually employed for corporate stewardship, either retrospectively (to reward performance), or prospectively (e.g., to assess an entity's solvency, or the management's capability at running an entity). Accounting conventions also shape corporate decisions because measurement and consolidation rules are an important determinant of firms' fiscal and regulatory constraints.

A global debate on the opportunity of fair-value accounting has been raging for years. The International Accounting Standard Board defines fair value as "the price that would be received to sell an asset or paid to transfer a liability in an orderly transaction between market participants at the measurement date." ${ }^{1}$ This contrasts with amortized-cost accounting whereby, broadly, items remain recorded at their entry value instead of reflecting all relevant data accruing from markets for similar items. ${ }^{2}$ Advocates of fair-value accounting (such as the International Accounting Standard Board) argue that marking to market provides a more accurate picture of the balance sheet, and prevents distortions such as gains trading (the selling of winners and keeping of losers under amortized-cost accounting). By contrast, opponents of fair-value accounting point at the volatility of market values, mispricing and the destabilization of balance sheets; they further worry about macroeconomic implications, such as the occurrence of fire sales by entities pressed to sell already-depreciated assets.

Presumably, the extent to which the information that firms convey to their stakeholders relies on market data should have a far-reaching impact on both corporate governance and capital markets. Yet, economists have devoted surprisingly little research to this question. The goal of this paper is to offer a framework for the study of accounting measures that builds on the primitive ingredients of information economics (informational asymmetries). The use of market data for measurement purposes (marking to market) and firms' decisions to shed mismeasured assets (taking to market) are the ingredients of an optimal mechanism that addresses these informational asymmetries. We are particularly interested in the mutual feedback between the design of privately optimal mechanisms by firms, and the liquidity and informational efficiency of the market for their assets.

Our starting point is a standard agency model of corporate finance in which the manager of a firm exerts effort to figure out a value maximizing strategy, which we simply model as the selection of a good project/asset. The manager's fate (monetary compensation, tenure, decision-making) must be decided before the asset pays off. While the

\footnotetext{
${ }^{1}$ See International Financial Reporting Standards 13.

${ }^{2}$ Some impairment rules may take sufficiently negative market signals into account under amortizedcost accounting. On the other hand, positive market signals per se do not lead to a change in book value.
} 
frontloading of managerial rewards is a familiar question in agency theory, the novelty of our approach lies in the set of early performance measures that stakeholders can use in the absence of any realized cash flows. The principal (the investors in the firm) can avail herself of a costless, but noisy public market signal, or/and obtain a more precise, but costly measure of asset value by reselling the asset. In the subsequent equilibrium model, the two performance measures will correspond to the price fetched by comparable assets traded by other firms and the asset's actual trading price, respectively. The initial partial equilibrium approach of Section 2 by contrast takes the precision of the market signal and resale transaction costs as exogenous and solves for the individually optimal contract.

A salient feature of this optimal contract is that asset sales consist only in realizing latent gains, never latent losses, even when transaction costs are smaller for latent losses. The reason is that addressing the ex-ante moral-hazard problem requires that the agent be rewarded for having selected a good project. The agent is rewarded in case of sufficiently good market news, as the firm can then economize on transaction costs without leaving a large undue rent to an underperforming manager. Upon bad market news, the manager is allowed to prove that the market signal is overly pessimistic by realizing a latent gain. Gains trades are typically viewed as an unintended consequence of amortized-cost accounting. This setup is the first, to our knowledge, to model gains trades as a component of an optimal mechanism. The optimal degree of marking to market in this mechanism trades off the cost of rewarding the agent for luck when relying on market data with the cost of inefficient gains trades as credible signals of good performance.

Section 3 then endogenizes the transaction costs associated with gains trading. It presumes imperfect competition in the resale market for firms' assets. Firms and informed buyers, who are able to assess the quality of an asset, are matched through a random process. The manager is in charge of selling the asset. The firm's investors observe only the realized resale price, if any, and optimally impose a reserve price on the manager. In equilibrium, the more intense the competition (the larger the number of informed buyers), the higher the bids and the lower the expected transaction costs. For firms, increasing the reserve price substitutes gains trading by marking to market, economizing on transaction costs while rewarding more for luck.

There can be two self-fulfilling degrees of liquidity in the market for assets, that correspond to two degrees of marking to market. Informed buyers bid aggressively when expecting a high reserve price, which reduces resale costs and discourages marking to market. This equilibrium is constrained efficient for a given number of informed buyers. There may also exist an illiquid equilibrium in which sales are costly, which in turn justifies relying less on sales, and relying instead heavily on mediocre signal realizations. This equilibrium with excessive marking to market and illiquid assets comes at a higher cost of capital for firms. It is unstable in the following sense. A mandated decrease in the degree 
of marking to market, however small, leads to the constrained-efficient equilibrium to be the unique equilibrium.

Finally, Section 4 endogenizes the competitiveness of the asset market among informed buyers through a free-entry condition. It also endogenizes market signals as publicly observed asset resales by firms executing their optimal contract. In such general equilibrium, laissez-faire leads to an excessive reliance on market signals. The reason is that firms fail to internalize the effect of their measurement systems on the liquidity of the items that they seek to measure, where liquidity is defined both in terms of ease of trading and of the informativeness of price signals. Under laissez-faire, firms contract too much on transactions by other firms. They sell their own assets too rarely, and at deep discounts when they do so. A regulation that limits the extent to which they mark their assets to market reduces their cost of capital by spurring informed buyers' entry. Taking to market is more efficient because asset resales occur at higher prices. So is marking to market because resale prices are more informative.

\section{Related Literature}

The three sections of this paper are related to different literatures. Section 2, which couches the trade-off between "relevance" and "reliability" within an optimal contracting framework, is most related to the agency literature on informativeness of performance measurement. Holmström (1979) proves that incentives should be based solely on a sufficient statistic of unobservable effort. Kim (1995) shows that information systems are ranked if the likelihood ratio distribution of an action choice under an information system is a mean-preserving spread of the likelihood ratio distribution under the other. Section 2 derives the optimal mix between using a free, but noisy external signal and using a costly, but more precise one obtained through resale. The paper shares with the literature on costly state verification initiated by Townsend (1979) and with the "varianceinvestigation" literature in accounting the idea that the optimal agency contract uses costly inspections so as to verify the agent's claim. Whereas negative reports lead to verification in this literature, positive reports do in our setup. Dye (1986) studies a principal-agent model in which the principal faces the related problem of optimally combining two sources of information, the agent's output and a direct but costly verification of her effort level. Our paper interprets the "verification cost" as a discount on an asset resale, and to the best of our knowledge, is the first to derive marking to market and gains trading as optimal features of an optimized information system.

There is a large literature on disclosure in accounting. A recent entry is Acharya et al (2011), who study the dynamics of loss recognition. In their paper, managers receive (verifiable) signals about the value of the firm and optimize over disclosure decisions; public information may accrue exogenously over time, and market news and value of the 
firm are correlated. The main result is that the accrual of negative public information accelerates the release of information by the firm (the information withheld may not be as bad as the market now expects). They also show that for the volume of disclosure to depend negatively on the public signal, managers must be able to pre-empt the release of external information by disclosing their own signal; and that bunching is more likely within an industry/similar group of firms. The focus is different from ours (disclosure rather than the costly sale of assets). Our analysis is also more normative.

Section 3 endogenizes resale costs by positing a matching process and a first-price auction among bidders. The reserve price is secret as in Elyakime et al (1994), in which the number of bidders is unlike here known. ${ }^{3}$ The key new feature relative to the auctions literature is that the seller does not have a set valuation. Rather, the reserve price is derived from a contracting problem, where the transaction cost of selling the asset is compared with the imprecision of the market signal and both jointly contribute to set the agent's incentives.

Like the literature on auctions with an endogenous number of bidders (e.g. LevinSmith 1994, Jehiel-Lamy 2015b), Section 4 endogenizes entry through a zero expected profit condition. And the seller benefits from a liquid market. ${ }^{4}$ The novelty is that liquidity depends on the accounting choices made by the other firms. This externality is at the core of our welfare analysis.

One can also draw an interesting analogy with the literature on thick-market externalities (Admati-Pfleiderer 1988, Pagano 1989). In that literature, investors with liquidity needs who are able to select their trading date prefer to bunch with other liquidity traders as this limits the ability of informed buyers to exploit mispricing and further may induce more competition among informed buyers. A common feature with our paper is that sellers' decisions (when to trade, extent of fair value accounting) affect the welfare of other sellers through the impact on informed trading. For instance, Admati and Pfleiderer endogenize information acquisition through a free-entry condition and show that the patterns of trading volume that exist in the model with a fixed number of informed traders become more pronounced if the number of informed traders is endogenous. Besides the obvious differences in focus (intraday trading volatility vs. accounting choices) and modelling (our model captures the decision of whether to bring the asset to the market rather than the choice of when or where to bring it to the market), our paper emphasizes the benefit (performance measurement), rather than the cost of informed trading.

\footnotetext{
${ }^{3}$ In their framework, Elyakime et al. prove that the seller would be strictly better off if he could commit to a reserve price. The same holds in our framework as well. Jehiel and Lamy (2015a) endogenize secret reserve prices through heterogeneous seller valuations.

${ }^{4}$ In Aghion et al (2004), the firm elicits buyer interest in the asset (which is also sold for performance measurement purposes) by forcing passive shareholders to tender their shares (drag-along institution). Here liquidity relies not on an internal design, but from accounting choices made by other firms.
} 
Finally, this paper relates to the burgeoning literature in accounting theory that studies the distorted incentives induced by an exogenously given accounting standard (see, e.g., Allen-Carletti 2008, Bleck-Gao 2012, Bleck-Liu 2007, Heaton et al. 2010, Otto-Volpin 2015, or Plantin et al. 2008). We extend this literature in two directions. First, in our environment, firms optimize both over accounting measures and trading decisions in the face of informational frictions. Second, we also take into account the equilibrium impact of these individual decisions on the cost of trading assets and on the quality of market data. We show that these two equilibrium effects are important and point at a socially excessive use of marking to market.

\section{Marking to market versus taking to market: a sim- ple framework}

\section{$2.1 \quad$ Model}

There are four dates $0,1,2,3$. There are two parties, a principal and an agent, involved in a project - a "firm" - that is initiated at date 0 and pays off at date 3 . The principal stands for outsiders, or constituencies that have a financial stake in the firm but do not operate its assets. The agent stands for insiders - the stakeholders who run the firm or closely oversee its operations, such as managers and directors.

The principal does not discount time and is risk neutral over consumption at each date. The cashless agent derives utility at date 2 only. The principal can provide the agent with any utility level $u \in[0,1]$ at date 2 at a monetary cost $u$. The important feature is that the agent's utility cannot be costlessly backloaded to date 3 , so that date- 2 measurements of the final cash flow matter for performance evaluation. ${ }^{5}$

Interpretations. The provision of utility to the agent admits several interpretations. First, it may simply be that the agent derives utility from consuming a pecuniary transfer from the principal. That his utility over consumption is locally linear and bounded above captures risk-aversion in the simplest fashion. ${ }^{6}$ A second interpretation is that the principal has the option to fire the agent at date 2 in order to hire a new one who can create more value out of the project. The initial agent derives a private benefit from remaining employed within the firm, but this comes at the opportunity cost for the firm of giving up this value. In our specification, the foregone value and the private benefit are both normalized to 1 . A third interpretation is that the principal may entrust the agent with a new project at date 2 . The agent derives a private benefit from running this project

\footnotetext{
${ }^{5}$ Section 2.3 discusses the more general case in which the agent discounts date-3 utility at a higher rate than the principal.

${ }^{6}$ Setting the upper bound at 1 saves on notation and comes at no loss of generality.
} 
(normalized to 1), but the project value net of this private benefit is negative (normalized to -1$)$.

The agent must select a project at date 0 . Projects may be of two types, 1 or 2 . Both types require the same date-0 investment outlay. One type of project pays off $h$ at date 3 , whereas the other type delivers $l$, where

$$
h>l .
$$

The principal and the agent have the common prior that a payoff of $h$ is associated with the type- 1 project with probability $1 / 2$. The principal observes the type of the project selected by the agent.

At date 0 , the agent receives a private signal about the payoff associated with each project type. The signal precision depends on an effort level secretly chosen by the agent. If the agent "behaves," the signal matches the true payoffs with probability $p$. If he "shirks," the signal is correct with probability $p-\Delta p$ only, where

$$
\frac{1}{2} \leq p-\Delta p<p<1
$$

By shirking, the agent derives a private benefit added to any utility he may receive from the principal and that we denote $b>0$.

In other words, the principal-agent relationship is plagued by a moral-hazard problem that takes the form of a nonobservable forecasting effort exerted by the agent. This effort stands for any time and resources that insiders devote to figuring out the strategy that generates the highest firm value. Depending on the context, such strategic decisions encompass asset allocation, market entry or exit, risk-management decisions, etc...This incentive problem creates a role for performance-based contracts.

The principal has two sources of information about the project's payoff before date 3. First, a public signal $s \in \mathbb{R}$ is available at date 1 . The distribution of this signal conditional on final payoff $y \in\{h ; l\}$ admits a continuous density $f_{y}(s)$ such that

$$
L(s)=\frac{f_{h}(s)-f_{l}(s)}{f_{l}(s)}
$$

is strictly increasing. For brevity, we will rule out some corner solutions by assuming that the signal can be arbitrarily informative and so the image of $L$ is $(-1,+\infty)$. We denote by $F_{y}$ the conditional c.d.f. of the signal. We interpret this date- 1 public signal as a publicly observed market price for assets that are comparable to that chosen by the agent. For notational simplicity, we assume that this signal is freely available. In practice, external pricing services and audit, or assessment of fair values may create a cost of obtaining this signal. The qualitative results however would not be affected by the introduction of a cost of observation. 
Second, the asset can be sold at date 2, yielding proceeds

$$
y-c_{y}
$$

when the date- 3 cash flow is $y \in\{h ; l\}$. The transaction costs $\left(c_{h}, c_{l}\right)$ are strictly positive and such that a sale perfectly reveals the date-3 payoff:

$$
h-c_{h}>l-c_{l} .
$$

More generally, $\left(c_{h}, c_{l}\right)$ could be the expected values of random costs, in which case (1) must hold for each possible cost realization. The interpretation of the public signal as market data and that of this date- 2 costly state verification technology as an asset resale anticipate the way they will be endogenized in Sections 3 and 4, in which (the stochastic version of) condition (1) will be satisfied.

The agent privately observes the date- 3 payoff from the project at date 1 after the public signal is realized. Figure 1 summarizes the sequence of events:

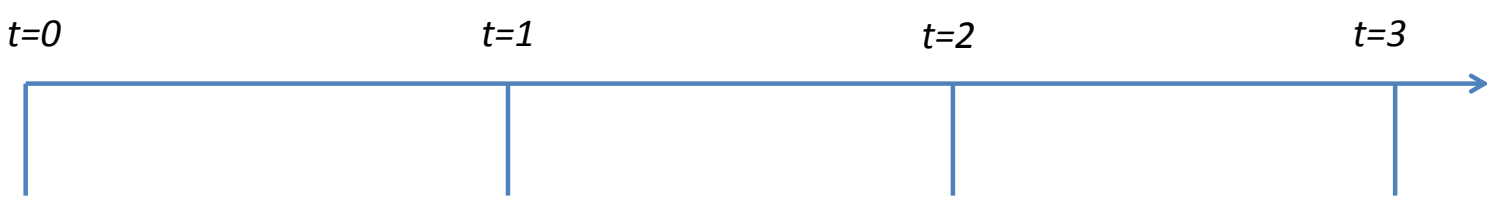

\section{- Principal and agent sign a - Public signals - Asset can be sold Asset pays off contract \\ - Agent exerts forecasting effort and selects a project type

Figure 1. Timeline.

\subsection{Optimal contract}

We suppose that the parameters are such that the relationship is socially desirable only if the agent behaves. We solve for the contract that minimizes the cost to the principal from inducing the agent to behave. ${ }^{7}$ We suppose that effort incentives can be provided:

$$
\Delta p \geq b
$$

\footnotetext{
${ }^{7}$ For brevity, we suppose that the participation constraints of the principal and the agent are always satisfied under this contract, so there is no binding financing constraint.
} 
This means that if the principal observed the date-3 payoff at date 2 , he could elicit effort by granting the agent utility $b / \Delta p$ whenever $y=h$. The ratio $b / \Delta p$ of the private benefit divided by the impact of shirking captures the extent of moral hazard. We denote it

$$
\beta \equiv \frac{b}{\Delta p}
$$

In such a second-best case, in which the principal-agent relationship is plagued only by a moral-hazard problem but not by a measurement problem, the expected cost for the principal to induce the agent to behave would be $p \beta$. We are interested in assessing the additional costs induced by the measurement problem.

Because the principal at date 2 has only access to measures of the terminal payoff, he writes a contract that specifies the circumstances under which either measure (signal or resale) is used to determine the compensation of the agent. We suppose that the principal can fully commit to a contract and we solve for the optimal contract. A general mechanism is such that the agent reports the value of the terminal cash flow to the principal at date 1. Based on this report and on the date- 1 public signal, the contact may command to hold the asset until maturity and compensate the agent at date 2. It may alternatively ask the agent to sell the asset at date 2, and compensate the agent on the basis of the signal, the report, and the observed sale price (which perfectly reveals the terminal cash flow). The optimal contract has a simple structure.

Proposition 1. (Optimal contract) The optimal contract is characterized by a threshold $\sigma$ and a probability $x$ such that:

- the agent receives utility 1 regardless of his report if the public signal is above $\sigma$;

- if the signal is smaller than $\sigma$ and the agent reports a high payoff, then with probability $x$ the contract asks him to sell the asset, and provides utility 1 if the sale confirms the report;

- the agent receives a zero utility otherwise.

The cost of capital for the optimal contract is

$$
p \beta+\left[1-F_{l}(\sigma)\right]+p x F_{h}(\sigma) c_{h} .
$$

Proof. See the appendix.

In words, the generic optimal contract rewards the agent if the signal is above a cutoff, or if it is below this cut-off and the agent is able to realize a latent gain. Note that, due to local risk-neutrality and fixed transaction costs, the threshold $\sigma$ and the probability $x$ are uniquely defined, but that there are several possible implementations 
of this contract when $x \in(0,1)$. Conditionally on a signal below $\sigma$, sales can occur with probability $x$ independently of the signal realization, or equivalently with probability 1 for signal realizations in any subset with measure $x$. The version of the model with convex transaction costs developed below lifts this indeterminacy.

Expression (2) is the expected cost of the project for the principal above and beyond the initial investment outlay. It is comprised of expected payments to the agent and expected resale costs. Slightly abusing terminology, we deem it the "cost of capital" throughout the paper, as it represents the difference between the expected future cash flows of the firm and the willingness to pay for them of its suppliers of capital. Each of the three terms in (2) admits a simple interpretation. The first term $p \beta$ is the second-best cost that would prevail absent measurement frictions. The two other terms represent the cost of the measurement frictions that we added to this standard agency problem. The second term, $1-F_{l}(\sigma)$, is the cost from rewarding the agent for luck when mistakenly using the public signal, whereas the last term, $p x F_{h}(\sigma) c_{h}$, represents the expected transaction costs from sales. The optimal contract trades off these latter two costs.

The determination of the parameters $(\sigma, x)$ that characterize the optimal contract is instructive. It amounts to finding a cut-off signal value $\sigma$ above which the agent is rewarded and a probability $x$ of selling a good asset under this cut-off value, such that the cost of capital is minimized subject to incentive-compatibility and feasibility constraints:

$$
\min _{\{\sigma, x\}}\left\{1-F_{l}(\sigma)+p c_{h} F_{h}(\sigma) x\right\}
$$

s.t.

$$
\begin{aligned}
& F_{l}(\sigma)-F_{h}(\sigma)+x F_{h}(\sigma)=\beta \\
& 0 \leq x \leq 1
\end{aligned}
$$

The incentive-compatibility constraint (4) is derived as follows. Effort raises the probability of a high outcome by $\Delta p$ at the cost of the private benefit $b$. A high outcome raises in turn the agent's expected utility due to favorable signal realizations by $\left(1-F_{h}(\sigma)\right)-\left(1-F_{l}(\sigma)\right)$ and that due to asset resales by $x F_{h}(\sigma)$. Thus the term $F_{l}(\sigma)-F_{h}(\sigma)$ in $(4)$ reflects the incentives that are provided to the agent through the market signal. The term $x F_{h}(\sigma)$ corresponds to that provided through asset resales. ${ }^{8}$

Ignoring the feasibility constraint (5), the first-order condition for this program reads:

$$
L(\sigma)=\frac{1}{p c_{h}} .
$$

\footnotetext{
${ }^{8}$ To obtain (3), note that the total cost of incentives for the firm is the sum of the expected compensation following a high signal $p\left[1-F_{h}(\sigma)\right]+(1-p)\left[1-F_{l}(\sigma)\right]$, the gains-trading compensation $p F_{h}(\sigma) x$, and the expected resale cost $p F_{h}(\sigma) x c_{h}$. Using (4) then yields $(3)$.
} 
Our assumption of a wide image for $L$ implies that there is an interior solution whereby

$$
\sigma=\widehat{\sigma} \equiv L^{-1}\left(\frac{1}{p c_{h}}\right)
$$

and $x \in(0,1)^{9}$; or a corner solution for which $x=0$ or $x=1$ and (in either case) $\sigma \geq \widehat{\sigma}$.

Intuitively, at the cut-off $\widehat{\sigma}$, the firm is indifferent between increasing the probability of resale or using a lower signal cut-off in order to raise incentives. The corner solution where $x=0$ corresponds to the case in which the signal is sufficiently informative other things being equal that the level of incentives $\beta$ is reached using only the signal with a cut-off above $\widehat{\sigma}$. The corner solution $x=1$ is conversely such that incentives are not sufficient when resale takes place only for signal realizations below $\widehat{\sigma}$. The firm must substitute marking to market by resale for signal values above $\widehat{\sigma}$ in this case.

It is interesting to define the degree of marking to market $m$ of a contract as the fraction of the total incentives that stem from the market signal:

$$
m \equiv \frac{F_{l}(\sigma)-F_{h}(\sigma)}{\beta} .
$$

Managerial accounting versus balance-sheet accounting. Under the interpretation that the agent is rewarded with an outright pecuniary transfer, the degree of marking-to-market $m$ simply measures the extent to which managerial compensation and thus managerial accounting are based on market data. Under the alternative interpretations in which incentives are provided through replacing the insiders of the firm, or entrusting them with a new project, the optimal contract admits an interpretation in terms of balancesheet measurement. In this case, the contract consists in implementing the strategy that is preferred by insiders (continuation, expansion,...) only if the firm has a sufficiently large book value of equity. This is the case if the updated firm value following the market signal is sufficiently high, or if the agent realizes a capital gain. ${ }^{10}$ A higher value of $m$ then means that corporate decisions rely relatively more on the fair valuation of the balance sheet.

Note that the degree of marking-to-market $m$ decreases in $\sigma$ in the relevant range since $L(\sigma)>0$. Figure 2 depicts $\sigma$ and $m$ as functions of $\beta$.

\footnotetext{
${ }^{9}$ This interior solution arises when the solution $x$ to $F_{l}(\widehat{\sigma})-F_{h}(\widehat{\sigma})+x F_{h}(\widehat{\sigma})=\beta$ lies between 0 and 1 .

${ }^{10}$ This provides an exact implementation of the optimal contract if $l$ is sufficiently small that the resale price is above the updated firm value following a market signal above $\sigma$ :

$$
\left[p f_{h}(\sigma) h+(1-p) f_{l}(\sigma) l\right] /\left[p f_{h}(\sigma)+(1-p) f_{l}(\sigma)\right] \leq h-c_{h} .
$$
}




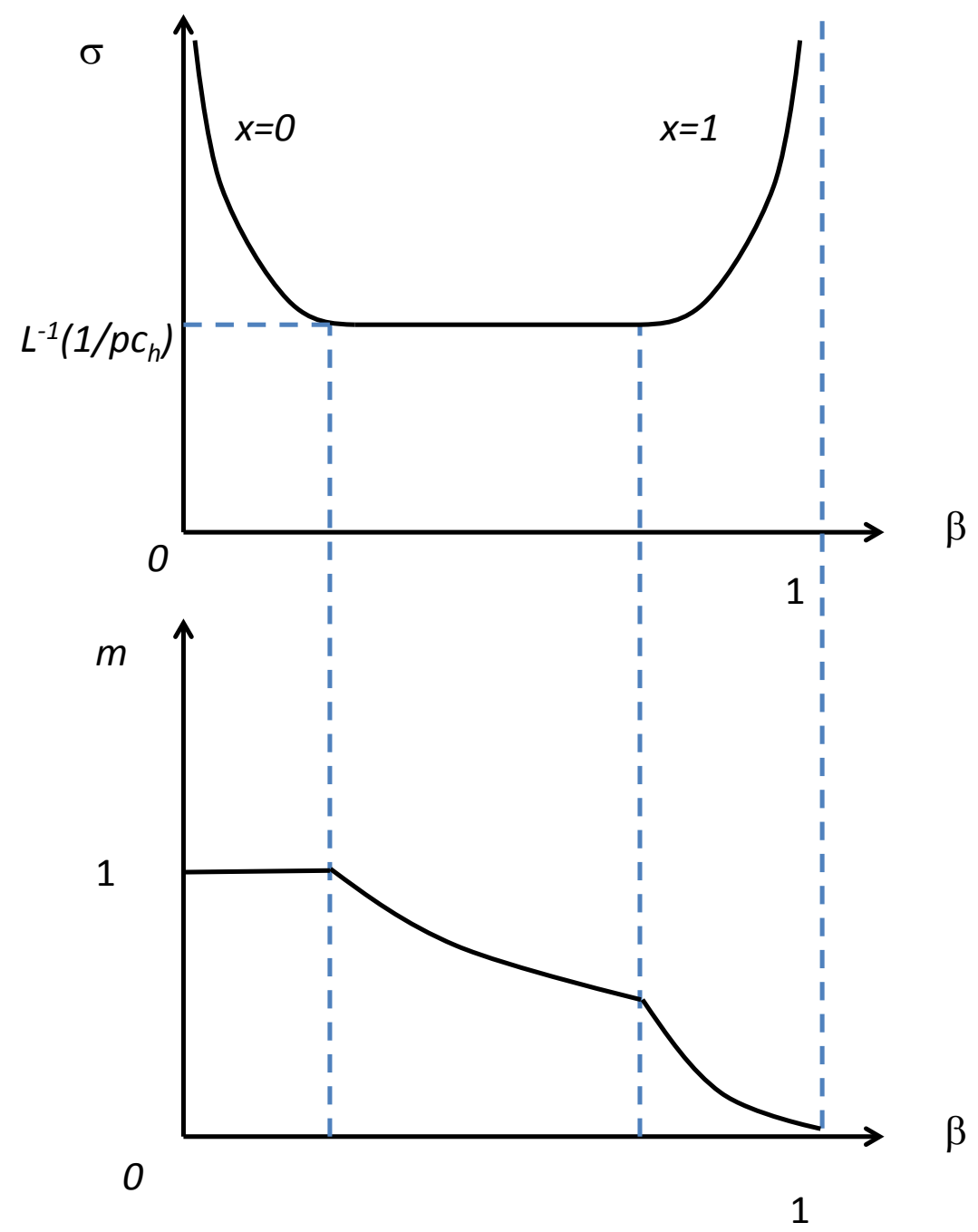

Figure 2.

Unsurprisingly, the degree of marking to market increases when, other things being equal, the ex-ante cost of rewarding the agent on the basis of a successful sale, $p c_{h}$, increases. This makes the use of the market signal relatively more appealing. More interestingly, the degree of marking to market $m$ decreases when the extent of moral hazard $\beta$ increases ceteris paribus, as shown in Figure 2. This is because the marginal cost of additional trading is constant whereas the marginal cost of relying more on the signal is increasing, in turn because the marginal probability that the agent is rewarded for luck increases as $\sigma$ decreases. The optimal contract relies therefore relatively more on sales as the overall need to provide incentives increases. Notice that this result hinges on the assumption of constant marginal trading costs.

The effect of signal quality on the degree of marking to market $m$ is best seen by the 
introduction of the modified likelihood ratio

$$
\Lambda(s) \equiv \frac{f_{h}(s)-f_{l}(s)}{p f_{h}(s)+(1-p) f_{l}(s)}=\frac{L(s)}{1+p L(s)} .
$$

Other things being equal, the degree of marking to market increases in a change in the signal's distribution if and only if this change implies that

$$
E\left[1_{\left\{\Lambda \geq \frac{1}{p\left(1+c_{h}\right)}\right\}} \times \Lambda\right]
$$

increases. ${ }^{11}$ Intuitively, it is optimal to rely more heavily on the signal when the likelihood ratio is more variable to the right of the cut-off $\Lambda(\sigma)$. Notice that an increase in the modified likelihood ratio $\Lambda$ in the sense of second-order stochastic dominance is neither necessary nor sufficient for $(7)$ to increase. ${ }^{12}$ In the simple case in which the signal is equal to the payoff plus Gaussian noise, it is easy to see that a reduction in noise leads to a higher degree of marking to market, though. The following proposition collects these results.

Proposition 2. (Degree of marking to market) In the optimal contract, the degree of marking to market $m$ increases with respect to trading costs $p c_{h}$. It also decreases with respect to the severity of the moral-hazard problem as measured by $\beta$. It may be that $m=1$ if the agency problem is sufficiently benign or if transaction costs are sufficiently large. Finally, a change in the signal's distribution leads to a higher degree of marking to market if and only if it leads (7) to increase.

\subsection{Agent's preference for liquidity and balance-sheet account- ing}

Throughout the paper, we take the agent's reward date as fixed $(t=2)$ for expositional simplicity. In this section, we more generally follow the literature on incentives provision for agents with liquidity needs ${ }^{13}$ and assume that delaying compensation to date 3 involves a social cost. Suppose that the agent derives utility at both dates 2 and 3 and has preferences

$$
u_{2}+\delta u_{3}
$$

\footnotetext{
${ }^{11}$ This stems from

$F_{l}(\sigma)-F_{h}(\sigma)=\int_{\sigma}^{+\infty} f_{h}(\sigma)-f_{l}(\sigma)=\int_{\sigma}^{+\infty} \Lambda(s)\left[p f_{h}(s)+(1-p) f_{l}(s)\right] d s=E\left[1_{\left\{\Lambda \geq \frac{1}{p\left(1+c_{h}\right)}\right\}} \times \Lambda\right]$.

${ }^{12} \mathrm{Kim}$ (1995) shows that an increase in the likelihood ratio of a signal in the sense of second-order stochastic dominance makes incentive-compatible contracting more efficient. Our criterion differs because it is only the right tail of signal realizations that matters in our setup.

${ }^{13}$ See e.g. Aghion et al (2004), or Faure-Grimaud-Gromb (2004).
} 
where $\delta, u_{2}, u_{3} \in[0,1]$. The principal can still provide the agent with utility $u_{t}$ at cost $u_{t}$ for $t \in\{2 ; 3\}$. The baseline model corresponds to the case in which $\delta=0$. The secondbest case without measurement frictions corresponds to $\delta=1$. It is straightforward to extend the analysis to the case in which $\delta \in(0,1)$. For brevity, we discuss only the case in which $\beta \leq \delta$ so that it is possible to incentivize the agent using only the date- 3 observed payoff. ${ }^{14}$

\section{Proposition 3. (Agent with liquidity needs)}

- If $\delta\left(1+c_{h}\right)<1$, then the optimal contract is the same as in the baseline model where $\delta=0$.

- If $\delta\left(1+c_{h}\right) \geq 1$, then the optimal contract consists in rewarding the agent at date 2 if the signal is above a cutoff $\sigma$, and to reward him at date 3 with some probability if the realized payoff is $h$.

Proof. See the appendix.

The principal can avail himself of two state-verification technologies - re-selling or waiting until the date-3 payoff realization. He uses the one that comes at the lowest cost. The optimal contract is the same as in the baseline model if the total resale cost $1+c_{h}$ is lower than the cost of rewarding at date $3,1 / \delta$. If, conversely, the cost of date- 3 rewards is lower, then there are no asset resales. The agent is rewarded at date 2 if the date- 1 signal is above a threshold. He is also rewarded at date 3 with some probability if the asset payoff is $h$. Date- 3 rewards need not depend on the date- 1 signal. The degree of marking-to-market decreases as $\delta$ increases in the region $\delta\left(1+c_{h}\right) \geq 1$, in which case the optimal contract relies more on date- 3 rewards.

As in the baseline model, this version lends itself to an interpretation whereby the agent's utility at each date corresponds to private benefits from a new investment by the firm that has a negative value net of these benefits. ${ }^{15}$ Under this interpretation, the optimal contract can be viewed again as one in which the firm invests at date 2 and/or 3 if its fair book value is sufficiently large at each date. When $\delta\left(1+c_{h}\right) \geq 1$, a lower degree of marking to market means that corporate decisions are primarily based on realized cash flows from operations.

This extension of the model bears interesting relationship to the accounting standard IFRS 9 issued in 2014. In this standard, the business model used by an entity for managing an asset affects the measurement of this asset. The "hold and collect" business model, whereby firms acquire assets to collect their cash flows until maturity, is the one that

\footnotetext{
${ }^{14}$ The proof of Proposition 3 solves for all cases.

${ }^{15}$ If the profitabilities of these investments are drawn from a continuous distribution, the probability of rewarding the agent at each date is optimally implemented with profitability thresholds.
} 
corresponds to the lowest degree of marking to market. In line with this, this simple extension predicts that firms with more patient agents (a higher $\delta$ other things being equal) rely more on the "hold to collect" model and, at the same time, use a lower degree of marking to market. Thus we rationalize this connection between "business model" and measurement regime.

\subsection{Imperfect competition in the resale market}

In preparation of the next section, we introduce imperfectly competitive bidding in the date- 2 market for projects as the source of resale costs. We model resales as follows. The agent is in charge of reselling the asset and thereby solicits bids at date 2 . The agent privately observes the bids received by the firm. The principal observes only whether the asset is sold and the price at which it is sold.

We make assumptions that later will be rationalized through optimal bidding by informed buyers. We assume that a project that pays off $y \in\{l ; h\}$ never elicits bids above $y$, that a $h$-payoff project elicits no bid with some probability $q_{0}$ and, with the complementary probability, receives a finite number of bids that are continuously distributed on an interval included in $(l, h]$. Finally, we assume that bids and the signal are independently drawn conditionally on the project type. We denote $H$ the c.d.f. of the highest bid received by a firm that has a $h$-payoff project, such that $H(b)=q_{0}$ for all $b$ below the lowest bid that the firm can receive. ${ }^{16}$

A formal mechanism is now such that after the signal $s$ is realized, the agent reports the project's payoff and then the received bids. ${ }^{17}$ The principal then makes resale and compensation decisions. The optimal contract has a similar structure to that in the baseline model:

Proposition 4. (Optimal contract with imperfectly competitive bids) The optimal contract is characterized by a threshold $\sigma$ and a reservation price $r$ such that:

- if the signal is above $\sigma$, then the agent receives utility 1 ;

- if the signal is below $\sigma$, then the principal allows him to sell the asset above a reserve price $r>l$, and provides utility 1 if the sale is executed above this price;

- the agent receives zero utility otherwise.

Proof. Let us denote by $u_{y}(s)$ the expected utility that the optimal contract grants to the agent when the signal is $s$ and he reports a project payoff $y \in\{l ; h\}$, and by $x_{y}(s)$

\footnotetext{
${ }^{16}$ This amounts to formalizing the absence of bids as receiving a highest bid equal to $-\infty$.

${ }^{17}$ That the agent privately observes the project payoff at date 1 is actually immaterial in this version of the model.
} 
the probability that the project will end up being sold in this case. These are date- 1 expectations - before the bids are observed at date 2. The expected cost of selling a project with payoff $y$ with a probability $x$ is a convex function $c_{y}(x)$ : The principal can achieve $x$ at the lowest cost by allowing the agent to sell the asset at the highest bid received if this bid is above some reservation price. ${ }^{18}$

For a given signal $s$, any report that does not lead to a resale (including for example reports that no bid has been received) must lead to the same compensation, which we denote $u_{0}(s)$. As is standard, we ignore the possibility that the high type mimics the low type, a non-binding constraint. This implies that low-payoff projects are never taken to market. Ignoring also the constraint that $x_{h}$ must lie between 0 and $1-q_{0}$, the optimal contract then solves:

$$
\min \left\{\int\left[p f_{h}(s)\left[u_{h}(s)+c_{h}\left(x_{h}(s)\right)\right]+(1-p) f_{l}(s) u_{0}(s)\right] d s\right\}
$$

s.t.

$$
\begin{aligned}
& \int\left[f_{h}(s) u_{h}(s)-f_{l}(s) u_{0}(s)\right] d s \geq \beta, \\
& \text { for all } s, u_{h}(s) \leq x_{h}(s)+\left[1-x_{h}(s)\right] u_{0}(s) .
\end{aligned}
$$

Condition (10) is the ex-ante incentive-compatibility constraint ensuring that the agent exerts maximum forecasting effort. Condition (11) reflects the fact that the high type's compensation is bounded by 1 if there is resale and by $u_{0}(s)$ if there is none. A simple inspection of the program shows that at the optimal contract, (10) and (11) must be binding. Substituting (11) in (10), and $\int\left[p f_{h}(s) u_{h}(s)-p f_{l}(s) u_{0}(s)\right] d s$ by $p \beta$ in (9) yields a Lagrangian:

$$
\mathfrak{L}\left(u_{0}(.), x_{h}(.), \alpha\right)=\int\left[\begin{array}{l}
{\left[\alpha\left[f_{h}(s)-f_{l}(s)\right]-f_{l}(s)\right] u_{0}(s)} \\
+\left[\alpha\left[1-u_{0}(s)\right] x_{h}(s)-p c_{h}\left(x_{h}(s)\right)\right] f_{h}(s)
\end{array}\right] d s-\alpha \beta-p \beta,
$$

where $\alpha$ is the shadow price of (10). Pointwise optimization yields that $u_{0}(s)=1_{\{s \geq \sigma\}}$, where $\alpha L(\sigma)=1$, and $x_{h}(s)=x 1_{\{s<\sigma\}}$ for some fixed $x$. This implies that the optimal contract is a pair $(\sigma, x)$ that solves the counterpart of $\{(3),(4)\}$

$$
\min _{\{\sigma, x\}}\left\{p F_{h}(\sigma) c_{h}(x)+1-F_{l}(\sigma)\right\}
$$

s.t.

$$
F_{l}(\sigma)-F_{h}(\sigma)+x F_{h}(\sigma) \geq \beta
$$

Still ignoring feasibility constraints on $x$, we have a first-order condition:

\footnotetext{
${ }^{18} \mathrm{An}$ arbitrary small increase in the compensation of the agent as a function of the resale price ensures that he has incentives to sell at the highest possible price.
} 


$$
\frac{f_{h}(\sigma)}{f_{l}(\sigma)}=\frac{1+p c_{h}^{\prime}(x)}{p c_{h}(x)+(1-x) p c_{h}^{\prime}(x)} .
$$

Note that this first-order condition becomes (6) when the marginal resale cost is constant.

In addition there may be binding feasibility constraints:

- If $\frac{f_{h}(\sigma)}{f_{l}(\sigma)}>\frac{1+p c_{h}^{\prime}(0)}{p c_{h}(0)+p c_{h}^{\prime}(0)}$ for the largest $\sigma$ such that $F_{l}(\sigma)-F_{h}(\sigma)=\beta$ if any, then the optimal contract is such that $x=0$.

- If $\frac{f_{h}(\sigma)}{f_{l}(\sigma)}>\frac{1+p c_{h}^{\prime}\left(1-q_{0}\right)}{p c_{h}\left(1-q_{0}\right)+q_{0} p c_{h}^{\prime}\left(1-q_{0}\right)}$ for the largest $\sigma$ such that $F_{l}(\sigma)-q_{0} F_{l}(\sigma)=\beta$ if any, the optimal contract is such that $x=1-q_{0}$.

It is important to note that this contract has the same broad structure as that in the baseline model. ${ }^{19}$ The main difference is that the expected cost of selling a good project with probability $x \leq 1-q_{0}$ is

$$
c_{h}(x)=\int_{H^{-1}(1-x)}^{+\infty}(h-t) d H(t),
$$

yielding an increasing marginal cost:

$$
c_{h}^{\prime}(x)_{\mid x=1-H(r)}=h-r .
$$

Using this change of variable $x=1-H(r)$, the first-order condition (15) can be rewritten as:

$$
\frac{f_{h}(\sigma)}{f_{l}(\sigma)}=\frac{p(h-r)+1}{p(h-r) H(r)+p \int_{r}^{h}(h-t) d H(t)} .
$$

This first-order condition captures that at the optimal contract, the firm is indifferent between asking a lower reserve price or marking to market at a lower signal cut-off to provide more incentives.

\subsection{The real effects of accounting measures}

The unintended consequences of accounting measures on firms' trading behavior have been fiercely debated. Historical-cost accounting has been accused of inducing costly and unnecessary realizations of latent capital gains ("gains trading") and equally costly

\footnotetext{
${ }^{19}$ Note that there exists an incentive-compatible contract if and only if

$$
\sup _{s}\left\{F_{l}(s)-q_{0} F_{h}(s)\right\}>\beta
$$
}

This condition is always satisfied in the baseline model in which $q_{0}=0$. 
concealment of latent losses. Marking to market has been accused, among other things, of contributing to a feedback loop between falling market prices and sell-offs during the 2008 crisis. $^{20}$ Interestingly, our setup in which accounting measures and trading behavior are jointly and optimally designed captures both gains trading and distressed sales upon bad market news as part of an optimal mechanism.

First, a salient feature of our optimal contract is that asset resales consist only in realizing latent gains, never latent losses. This is so regardless of the value of the transaction cost in case of a low cash flow $c_{l}$ (that is, even if $c_{l}=0$ ). The reason is that addressing the ex-ante moral-hazard problem requires that the agent be rewarded for having selected a good project and punished for having selected a bad one. Such a compensation scheme implies that ex post, an agent with a bad project has incentives to pretend otherwise whereas an agent with a good project has no reason to lie. Only claims that the project is good therefore need to be validated with a costly sale. Thus, our setup predicts that a lower degree of marking to market should come with more inefficient "gains trades" by firms. Gains trades are typically viewed as an unintended consequence of amortized-cost accounting. This setup is the first, to our knowledge, to explain a low reliance on market data and important gains trades as joint features of an optimal mechanism.

Second, sufficiently bad market signals trigger asset sales in the optimal contract. Interpreting this as distressed sales is admittedly a stretch at this stage. In anticipation of the next sections, we will establish a relationship between a high degree of marking to market and sales at deep discounts upon bad market news in equilibrium. First, we will show that firms tend to use contracts with inefficiently low cut-offs $\sigma$ in equilibrium, and to sell their assets at inefficiently low prices upon signal realizations below $\sigma$. Second, we will endogenize bad market signals for a project type as publicly observed resales of such projects at particularly low prices. This creates room for contagious distressed sales.

Sell-offs during the 2008 crisis were typically interpreted as "fire sales," whereby sales of illiquid assets depress their prices, which in turn weakens balance sheets and triggers more sales. The rationale for resales at deep discounts is entirely different here. Firms sell upon bad market news in order to prove that the market signal is overly pessimistic.

Finally, an interesting feature of the model for the political economy of accounting is that the total cost of capital for firms is split into expected payments to insiders and resale costs. The higher the degree of marking to market, the larger the fraction of these payments that accrue to insiders: Rewards for luck are more likely when the signal cut-off is lower. Managers benefit from a higher degree of marking to market.

\footnotetext{
${ }^{20}$ Ellul et al. (2015) document both types of distorted trading strategies in the case of U.S. insurance companies. Laux and Leuz (2010) oppose the view that marking to market played a substantial role during the 2008 crisis.
} 


\section{Endogenous resale prices}

This section endogenizes the transaction costs faced by firms in the date-2 market for their projects.

\subsection{Baseline model}

There are a continuum of firms with unit mass. Each of them faces the same situation as that described in the previous section. In particular, the payoff from each project type is the same for all firms. Date-0 private signals are independent across agents. The project type chosen by a firm is not observed by other firms. Each firm receives a signal about its project payoff at date 1 whose conditional distributions $f_{h}, f_{l}$ are identical across firms and have the same properties as in the previous section. The joint distribution of the signals is immaterial for our analysis.

The economy is also populated by a continuum of informed buyers with mass $\lambda$ who are risk-neutral over consumption at each date and know the payoff associated with each project type.

Firms can sell their assets to the informed buyers in a decentralized market at date 2. Firms and buyers interact as follows. Each buyer is randomly matched to a firm running the type of project ( 1 or 2 ) that he wants to bid for. ${ }^{21}$ Without observing how many fellow buyers are matched with this firm, he submits a bid. Only the agent of the firm observes the bids submitted by the matched buyers (if any). The principal observes only if a sale goes through and at which price if it does.

We construct equilibria with optimal incentive-compatible contracts. Informed buyers do not match with low-payoff projects in equilibrium because the resale of such projects cannot be part of an optimal contract. The matching technology is such that a firm with a high-payoff project is matched with $k$ bids with probability $q_{k}$. From Section 2.4, each firm designs a contract $(\sigma, r)$ such that the agent is rewarded if the signal is above $\sigma$, or if it is below $\sigma$ and he manages to sell the asset at some price larger than $r$. Anticipating such contracts, but without observing them, informed buyers place bids for the good project type according to a distribution with c.d.f. $S$. Put differently, equilibrium bidding involves a symmetric mixed strategy over bids with c.d.f. $S$. An equilibrium is then a triplet $(\sigma, r, S)$ such that:

- Each firm finds the contract $(\sigma, r)$ optimal given $S$.

- Each bidder is indifferent between each bid for a good project in the support of $S$.

\footnotetext{
${ }^{21}$ This assumption of directed matching simplifies the analysis but is not substantial. We discuss the case of non-directed matching at the end of the section. Also, that each buyer meets with one firm is only a normalization.
} 
In order to characterize equilibria, we first study buyers' strategies and then firms' contracting decisions.

Bidding strategies. We show in the appendix that the distribution according to which buyers mix their bids for a good project, $S$, is either a Dirac delta at $h$, or is atomless. $^{22}$ The lower bound of its support must be equal to the bidders' (correct) expectation of $r .^{23}$

This latter property has the key implication that the equilibrium probability that the sale of a good project fails to go through depends only on the absence of a knowledgeable buyer due to random matching. Thus it must be that in equilibrium, the probability of resale of an asset taken to market is $1-q_{0}$. This implies that the incentive-compatibility constraint (14) reads in equilibrium:

$$
F_{l}(\sigma)-q_{0} F_{h}(\sigma)=\beta
$$

Optimal contracts. We suppose that the bidders' mixing strategy $S$ is not degenerate, and we denote $r_{0}$ its lower bound. Each firm then faces a highest-bid distribution $H$ such that

$$
H=\sum_{k \geq 0} q_{k} S^{k}
$$

with again the convention that an absence of bid is a bid equal to $-\infty$. Each firm designs a contract $(\sigma, r)$ such that the incentive-compatibility constraint (14) binds and the firstorder condition (17) is satisfied if possible. This implies that the reservation price $r$ is either such that $r>r_{0}$, in which case a binding first-order condition yields:

$$
\frac{f_{h}(\sigma)}{f_{l}(\sigma)}=\frac{p(h-r)+1}{p(h-r) H(r)+p \int_{r}^{h}(h-t) d H(t)},
$$

or is such that $r=r_{0}$, in which case

$$
\frac{f_{h}(\sigma)}{f_{l}(\sigma)} \geq \frac{p\left(h-r_{0}\right)+1}{p\left(h-r_{0}\right) H\left(r_{0}\right)+p \int_{r_{0}}^{h}(h-t) d H(t)} .
$$

In the remainder of the paper, we assume away equilibria in which inequality (18) is strict, as the reservation price is then a weakly dominated strategy. ${ }^{24}$ This rules out a continuum of uninteresting equilibria with arbitrarily aggressive bids. It also implies that if the optimal contract is such that $\sigma=+\infty$, then it must be such that $r(s)=h$ for all $s$ : The absence of transaction costs then makes it suboptimal to ever use the market signal.

We are now equipped to characterize the equilibria. First, we have:

\footnotetext{
${ }^{22}$ See proof of Lemma 5.

${ }^{23} \mathrm{Id}$.

${ }^{24}$ One can eliminate such equilibria by assuming, for example, that a fee that is arbitrarily small on average but has full support over $[0, b-l)$ is shaved of each bid $b$.
} 
Lemma 5. An equilibrium contract $(\sigma, r)$ is either such that $\sigma=+\infty$ and $r=h$ or satisfies

$$
\begin{aligned}
& \frac{f_{h}(\sigma) q_{0}}{f_{l}(\sigma)}=\frac{1+\frac{1}{p(h-r)}}{1+\frac{\lambda q_{1}}{p q_{0}\left(1-q_{0}\right)}} \\
& F_{l}(\sigma)-F_{h}(\sigma) q_{0}=\beta .
\end{aligned}
$$

Proof. See the appendix.

The existence and number of equilibria then depend on the extent of moral hazard as follows. We let:

$$
\begin{aligned}
\sigma^{*} & \equiv L^{-1}\left(\frac{1-q_{0}}{q_{0}}\right), \\
\bar{\beta} & \equiv F_{l}\left(\sigma^{*}\right)-q_{0} F_{h}\left(\sigma^{*}\right)>1-q_{0} .
\end{aligned}
$$

Proposition 6. (Equilibria with endogenous resale prices) If $\beta>\bar{\beta}$, there is no equilibrium with incentive-compatible contracts. If $\beta \leq \bar{\beta}$,

- there exists a unique equilibrium in which the contract $(\bar{\sigma}, \bar{r})$ is such that $f_{h} q_{0} / f_{l} \geq 1$. If $\beta>1-q_{0}$, then $\bar{\sigma}$ is finite and $\bar{r}<h$. If $\beta \leq 1-q_{0}$, the equilibrium contract consists in selling the good asset at the price $h$ with probability $\beta /\left(1-q_{0}\right)$ (secondbest).

- If $\beta$ is sufficiently large, there also exists a unique equilibrium in which the contract $(\underline{\sigma}, \underline{r})$ is such that $f_{h} q_{0} / f_{l}<1$. It is such that $(\underline{\sigma}, \underline{r}) \leq(\bar{\sigma}, \bar{r})$.

Proof. The results in Proposition 6 are easy to see from Figure 3, which depicts the left-hand side of the incentive-compatibility constraint (20). 


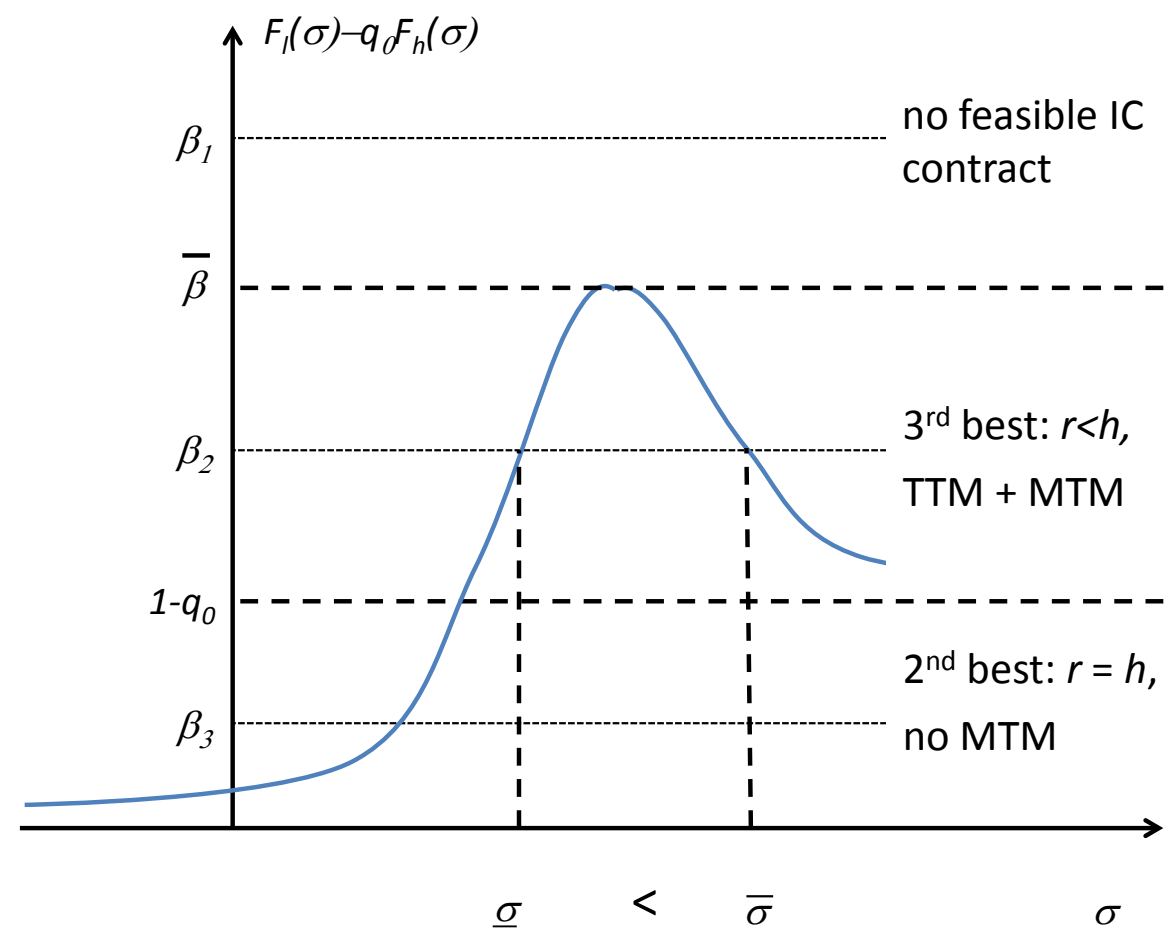

Figure 3. Equilibria for three values of $\beta$

The situation in which incentive-compatible contracts cannot be supported in equilibrium corresponds to $\beta=\beta_{1}$ in Figure 3 . This occurs when the agency problem is severe $(\beta$ large), the asset market is illiquid ( $q_{0}$ large), and the signal poorly informative $\left(F_{l} \simeq F_{h}\right)$.

Otherwise, if $\beta \in\left(1-q_{0}, \bar{\beta}\right]$ (case $\beta=\beta_{2}$ in Figure 3 ), then the incentive-compatibility constraint has two solutions, $\underline{\sigma} \leq \sigma^{*}$ where the function $F_{l}-q_{0} F_{h}$ is increasing $\left(f_{h} q_{0}<f_{l}\right)$, and $\bar{\sigma} \geq \sigma^{*}$ where the function $F_{l}-q_{0} F_{h}$ is decreasing $\left(f_{h} q_{0}>f_{l}\right)$. The latter always corresponds to an equilibrium ( $\bar{r}$ is then given by (19)), whereas the former does so only if $\beta$ is sufficiently large that there exists a $\underline{r}<h$ that solves (19) at $\underline{\sigma}$.

If $\beta \leq 1-q_{0}$ (case $\beta=\beta_{3}$ in Figure 3 ), then the second-best in which firms provide incentives only by selling their good projects at price $h$ with probability $\beta /\left(1-q_{0}\right)$ is the unique feasible equilibrium such that $f_{h} q_{0} / f_{l}>1$ because contracts with a finite $\sigma$ cannot be incentive compatible unless $f_{h} q_{0} / f_{l}<1$. This second-best cannot be supported otherwise because firms have to use the public signal together with resales. Finally, the unique cut-off $\underline{\sigma}$ that solves (20) when $\beta \leq 1-q_{0}$ may or may not correspond to an equilibrium for $\beta$ sufficiently close to $1-q_{0}$ depending on other parameter values.

Note that it is possible that $r<l$ in equilibrium because agents make reports at date 1 before observing bids at date 2 , and thus any out-of-equilibrium bid for an $l$-project occurs after the payoff is revealed. In the version of the model with non-directed matching 
developed in Section 3.2, we will see that, conversely, any equilibrium must be such that the reserve price is larger than $l$.

The equilibrium probability of success of a resale is $1-q_{0}$, imposed by the matching technology, because buyers always bid above their (correct) expectation of the reserve price set by firms in equilibrium. But then this reserve price must adjust so that firms are indifferent between taking to market and marking to market at the signal cut-off of the optimal contract. There are two pairs $(\underline{\sigma}, \underline{r}) \leq(\bar{\sigma}, \bar{r})$ for which this is the case. If informed buyers expect a high reservation price $\bar{r}$, they bid aggressively. In this liquid equilibrium, resale costs are low, and thus firms rely on market data only when it is very informativehence a low degree of marking to market $\bar{\sigma}$. When $\beta \leq 1-q_{0}$, this liquid equilibrium takes the extreme form of the second-best in which firms sell their assets at the maximum price and do not use market data at all. There may also exist an illiquid equilibrium in which sales are costly, which in turn justifies relying less on sales, and relying instead heavily on mediocre signal realizations. In this illiquid equilibrium, the degree of marking to market is higher than in the liquid one. Asset sales are rare and occur at distressed prices upon the realization of very negative signals. This illiquid equilibrium is inefficient in the sense that it comes at a higher cost of capital for firms. ${ }^{25}$

The possibility that the equilibrium outcome yields excessive marking to market jointly with distressed sales is interesting. Yet, equilibria such that $f_{h} q_{0} / f_{l}<1$ are unstable whereas those such that $f_{h} q_{0} / f_{l}>1$ are stable and constrained-efficient in the following sense. Suppose that a regulation prevents firms from rewarding their agents based solely on the signal for signal realizations $s<\sigma^{\prime}$. We deem such regulated contracts " $\sigma^{\prime}$ contracts".

Proposition 7. (Regulating marking to market) Suppose there are two equilibria $(\underline{\sigma}, \underline{r}) \leq(\bar{\sigma}, \bar{r})$.

- The illiquid equilibrium $(\underline{\sigma}, \underline{r})$ is unstable: For every $\sigma^{\prime} \in(\underline{\sigma}, \bar{\sigma}]$, the only equilibrium with $\sigma^{\prime}$-contracts is the one with the contract $(\bar{\sigma}, \bar{r})$.

- The liquid equilibrium $(\bar{\sigma}, \bar{r})$ is constrained efficient: If $\sigma^{\prime}>\bar{\sigma}$, there is no equilibrium with incentive-compatible $\sigma$ '-contracts.

Proof. See the appendix.

In other words, it is possible to move the economy towards the equilibrium with the lowest cost of capital with a simple upper bound on the degree of marking to market - a lower bound $\sigma^{\prime}$ on the informativeness of the signal that firms can use to mark to market. The broad intuition why the inefficient equilibrium is unstable is as follows. Because $f_{h} q_{0} / f_{l}<1$ at this equilibrium, imposing an increase in the cut-off $\sigma$ generates higher

\footnotetext{
${ }^{25}$ See proof of Lemma 5.
} 
incentive provisions. Firms would like to respond with higher reserve prices because they can then afford a lower probability of successful resale. But since buyers always at least match this reserve price, this probability cannot decrease, and reserve prices and signal cut-offs must keep increasing until the efficient equilibrium is reached. On the other hand, when this efficient equilibrium features a finite $\bar{\sigma}$, such a regulation of marking to market, if too tight, may destroy firms' ability to write incentive-compatible contracts at all.

We believe that setting the intensity with which an accounting standard marks items to market can act as such a device to control the degree of marking to market in practice. To be sure, firms are always free to use whichever information they see fit when contracting, regardless of the prevailing accounting standard. Still, we believe that accounting standards that make a more or less intensive use of fair value can partially affect the degree of marking to market used by firms when contracting with their various stakeholders. This is because accounting measures are easier to use than bespoke variables for private contracting between heterogeneously informed agents in practice (e.g., in bond covenants) because they are familiar, available at no cost, certified, and easier to verify by courts.

\subsection{Extensions}

\section{The case of non-directed matching}

The baseline model considers the case in which buyers can direct their matches towards firms running a given type of projects, and so $l$-firms face no buyers in equilibrium. This corresponds to the situation in which buyers study firms after observing their project choices. Suppose conversely that buyers match with the entire population of firms, and observe the project type that they bid for only after being matched to a firm. In this case, any equilibrium must be such that $r \geq l$. Suppose otherwise. Then firms must reward an $l$-report with a payment equal to the expected probability of resale of an $l$-project, so that managers of $l$-projects do not misreport and try their luck with a resale. It is easy to see that this cannot be an optimal contract: raising the reserve price for resale of good projects from $r$ to $l$ both raises incentives and reduces firms' cost of capital. Equilibria may then be of two types. If $l$ is sufficiently small holding other parameters fixed (or if $h-l$ is sufficiently large holding $p h+(1-p) l$ constant), equilibria are such that $r>l$, the first-order condition (18) is binding, ${ }^{26}$ and the cut-off $\sigma$ solves (20). Otherwise, equilibria with incentive-compatible contracts are such that $r=l,(18)$ is slack, and the cut-off $\sigma$ solves $(20)$.

\footnotetext{
${ }^{26}$ The only modification to (18) in the case of non-directed matching is that the ratio of buyers to sellers is $\lambda$ instead of $\lambda / p$.
} 


\section{Uncertain liquidity}

Suppose that firms must write contracts before observing the mass of informed buyers $\lambda$. They share the prior that $\lambda$ is distributed according to the c.d.f. $\Lambda$. After agents have exerted their forecasting effort, the value of $\lambda$ is publicly observed by firms and buyers. The optimal equilibrium contract is now $(\sigma(\lambda), r(\lambda))$, contingent on the realization of $\lambda$. Suppose that the matching probabilities are such that $q_{k+1}(\lambda) / q_{k}(\lambda)$ increases in $\lambda$ for all $k$. This implies in particular that the number of buyers per firm increases with $\lambda$ in the sense of first-order stochastic dominance. We have:

Proposition 8. (Uncertain liquidity) The equilibrium contract is such that the reserve price is a constant $r$ and the signal threshold $\sigma(\lambda)$ is an increasing function of $\lambda$.

Proof. See the appendix.

In the presence of uncertain liquidity, firms equate the marginal cost of a resale across states $(r$ constant). Because the average resale cost decreases in $\lambda$, firms raise the cut-off above which they reward agents based on the signal as the market becomes more liquid, and thus rely more on resales in this case.

Following the 2008 financial crisis, regulators across the globe have temporarily suspended marking to market (or marking to model) for several banks' asset classes. The motivation was that, due to an abnormal lack of buyers, transaction data was irrelevant and would have triggered inefficient fire sales. The ex-ante optimal rule established in Proposition 8 relates to such decisions. In illiquid times, firms optimally ignore low transaction signals: They do not punish agents following such signals and avoid very costly resales.

\section{Endogenous liquidity}

This section studies the case in which the mass $\lambda$ of informed buyers is endogenously determined through a free-entry condition. We also endogenize the market signal received by each firm as the imperfect observation of transactions by other firms. Endogenous liquidity $\lambda$ affects firms' environment by impacting the matching process between firms and informed buyers, and in turn the quality of market data resulting from their interactions. We first assume a general form for the dependence of the date- 1 signal on the liquidity parameter $\lambda$, and then offer examples of microfoundations.

\subsection{A general model}

We suppose that there are a continuum of initially uninformed potential buyers with arbitrarily large mass. Each of them can privately observe the payoff of each project type 
before being matched to a firm by incurring a cost $\kappa>0$. We also assume that there is a large number of a third type of assets up for sale that uninformed bidders, unlike informed ones, cannot identify. We suppose that these assets have a sufficiently low payoff that uninformed bids are always below the equilibrium reserve price set by firms. The mass of informed bidders is now an equilibrium outcome $\lambda$.

Section 3 corresponds to the situation in which the information acquisition cost is a step function of $\lambda$ from zero to a large value so that $\lambda$ is completely inelastic. By contrast, with such a fixed cost $\kappa$, liquidity $\lambda$ now responds elastically to firms' decisions and impacts them in turn as follows. First, we assume that the matching process $\left(q_{k}(\lambda)\right)_{k \in \mathbb{N}}$ is well-behaved in the following sense:

Assumption. (Informed trading generates liquidity.) The functions $\left(q_{k}(\lambda)\right)_{k \in \mathbb{N}}$ are continuously differentiable over $(0,+\infty), q_{k+1}(\lambda) / q_{k}(\lambda)$ increases in $\lambda$ for all $k$, and $q_{1}(\lambda) /\left[q_{0}(\lambda)\left(1-q_{0}(\lambda)\right]\right.$ is increasing.

The condition that $q_{k+1} / q_{k}$ increases implies that the number of buyers per firm increases with $\lambda$ in the sense of first-order stochastic dominance. The condition on $q_{1} /\left[q_{0}\left(1-q_{0}\right)\right]$ means that an increase in $\lambda$ has a relatively stronger impact on liquidity (in the sense of a reduction in $q_{0}$ ) than on competition among buyers (through a reduction in the conditional probability of a monopsony $\left.q_{1} /\left(1-q_{0}\right)\right)$. These conditions are satisfied, for example, with an urn-ball process where $q_{k}(\lambda)=(\lambda / p)^{k} e^{-\lambda / p} / k !{ }^{27}$

Second, we also suppose that the c.d.f. of the date- 1 signal conditional on a payoff $y \in\{h ; l\}$ is of the form $F_{y}(s, \lambda)$, continuously differentiable with respect to $\lambda$, and satisfies:

Assumption. (Informed trading generates better market data.) For all $(s, \lambda)$,

$$
f_{l}(s, \lambda) \frac{\partial F_{h}(s, \lambda)}{\partial \lambda} \leq \min \left\{0 ; f_{h}(s, \lambda) \frac{\partial F_{l}(s, \lambda)}{\partial \lambda}\right\}
$$

This means that $F_{h}$ must increase with $\lambda$ in the sense of first-order stochastic dominance, and sufficiently more so than $F_{l}$. This property will arise naturally in the next section that endogenizes the signal. ${ }^{28}$

An equilibrium is then a triplet $(\sigma, r, \lambda)$ such that $(\sigma, r)$ defines an equilibrium in the sense of the previous section given $\lambda$, and potential buyers are indifferent between becoming informed or not given $(\sigma, r, \lambda)$. Note that the second-best equilibrium whereby firms use only sales at $r=h$ can no longer be sustained in this case as this precludes

\footnotetext{
${ }^{27}$ Recall that under directed matching, a mass $\lambda$ of informed buyers is matched with a mass $p$ of firms with high-payoff projects in equilibrium.

${ }^{28}$ Condition (21) obviously holds if $F_{h}$ increases whereas $F_{l}$ decreases in $\lambda$ in the sense of first-order stochastic dominance.
} 
information acquisition by buyers. As a result, an equilibrium with information acquisition $(\lambda>0)$ must satisfy the first-order condition (19), the incentive-compatibility constraint (20), and a free-entry condition:

$$
\begin{aligned}
& \frac{f_{h}(\sigma, \lambda) q_{0}(\lambda)}{f_{l}(\sigma, \lambda)}=\frac{1+\frac{1}{p(h-r)}}{1+\frac{\lambda q_{1}(\lambda)}{p q_{0}(\lambda)\left(1-q_{0}(\lambda)\right)}}, \\
& F_{l}(\sigma, \lambda)-F_{h}(\sigma, \lambda) q_{0}(\lambda)=\beta, \\
& F_{h}(\sigma, \lambda) \frac{q_{1}(\lambda)(h-r)}{1-q_{0}(\lambda)}=\kappa .
\end{aligned}
$$

In this section we focus on equilibria such that $f_{h} q_{0} / f_{l}>1$ that are stable in the sense defined in Section 3. We have:

Proposition 9. (Existence of a stable equilibrium) If there exists $\lambda$ such that $q_{0}(\lambda)>1-\beta,{ }^{29}$ there exists $\bar{\kappa}$ such that for all $\kappa \leq \bar{\kappa}$, there exists a stable equilibrium.

Proof. See the appendix.

Section 3 showed that stable equilibria are constrained-efficient when $\lambda$ is inelastic, in the sense that $\sigma^{\prime}$-contracts cannot be incentive compatible when $\sigma^{\prime}$ is strictly above the cut-off used in a stable-equilibrium contract. We now show that, conversely, laissez-faire is generically inefficient when $\lambda$ responds elastically to firms' behavior. Suppose that there exists a stable equilibrium $(\sigma, r, \lambda)$, but that firms are forced to use a regulated contract with a cut-off $\sigma^{\prime}>\sigma$ for marking to market.

Proposition 10. (Excessive marking to market under laissez-faire) If $\sigma^{\prime}>\sigma$ is sufficiently close to $\sigma$, then

1. There exists an incentive-compatible equilibrium with regulated contracts.

2. Such equilibria feature a lower cost of capital than under laissez-faire. There are more informed buyers, firms set more aggressive reserve prices, bidders bid more aggressively, and market signals are more informative.

Proof. See the appendix.

Bidders bid more aggressively in the regulated equilibrium in the sense that the distribution of their bids dominates the laissez-faire one according to first-order stochastic

\footnotetext{
${ }^{29}$ This condition ensures that $(23)$ admits a solution such that $f_{h} q_{0} / f_{l}>1$. It is satisfied for every $\beta \in(0,1)$ for an urn-ball matching process.
} 
dominance. Thus, laissez-faire is associated with excessive reliance on market signals and resales at excessively large discounts. ${ }^{30}$

The intuition for this result is simple. Firms fail to internalize the positive liquidity externalities that they create for each other by taking to market instead of relying on the public signal. Forcing them to adopt a higher confidence level when relying on marketbased evidence induces more trades and yields an increase in $\lambda$. This increase in $\lambda$ reduces firms' cost of capital through two channels. First, even if signal distributions were not affected by $\lambda$, curbing marking to market would still reduce firms' cost of capital as they would benefit from a larger pool of informed buyers and could afford more aggressive resale pricing. Second, in addition, they also benefit from a higher quality of market data. This latter effect exists only if inequality (21) holds strictly at the equilibrium.

\subsection{Public signal as observed transaction prices}

We now offer two microfoundations for the date-1 signal received by each firm. A first approach assumes that firms are subject to misclassification risk. They imperfectly identify the types of the projects sold by other firms. A second approach posits that firms' projects have an idiosyncratic component so that the market value of a particular project is a noisy signal about its type.

\section{Misclassification risk}

We merge dates 1 and 2 in the model of Section 4.1, and suppose that each firm observes asset resales by other firms before making its own trading and compensation decision at this date. ${ }^{31}$

This observation is imperfect, however. Each firm can collect data on the trading outcome for a sub-continuum of projects taken to market. It imperfectly identifies projects' types when collecting this data. A fraction $\rho$ of firms in the sample runs the same type of project as that of this firm, whereas the residual $1-\rho$ actually has a project of the other type. This accuracy parameter $\rho \in[0,1]$ is i.i.d. across firms and admits a c.d.f. $G$ that is strictly convex and admits a continuous density $g$. A firm does not observe its own accuracy parameter $\rho$. Thus, it believes that the fraction of successfully trading firms in its sample should be distributed as $\left[1-q_{0}(\lambda)\right] \rho$ if it has a high-payoff project and

\footnotetext{
${ }^{30}$ Note that Proposition 10 studies the case in which $\sigma^{\prime}$ is the exact cut-off that firms must use, rather than a lower bound on their contractual cut-offs as in Section 3. If regulation was only a lower bound on the cut-off, then we would need to ensure that the cost of capital is also reduced if the economy moves to another equilibrium than the initial one. In particular this new equilibrium must be stable. One can show that his holds in one of the examples studied in the next section (idiosyncratic risk).

${ }^{31}$ This is similar to the reduced-form for dynamics in rational expectations equilibria where agents condition their demand schedules on contemporaneous prices.
} 
as $\left[1-q_{0}(\lambda)\right](1-\rho)$ if it has a low-payoff project. This implies signal distributions:

$$
\begin{aligned}
& F_{h}(s, \lambda)=G\left(\frac{s}{1-q_{0}(\lambda)}\right) \\
& F_{l}(s, \lambda)=1-G\left(1-\frac{s}{1-q_{0}(\lambda)}\right),
\end{aligned}
$$

and

$$
\frac{f_{h}(s, \lambda)}{f_{l}(s, \lambda)}=\frac{g\left(\frac{s}{1-q_{0}(\lambda)}\right)}{g\left(1-\frac{s}{1-q_{0}(\lambda)}\right)}
$$

is increasing in $s$ by convexity of $G{ }^{32}$

Proposition 11. (Misclassification risk) Under misclassification risk, condition (21) is satisfied and thus Proposition 10 applies.

Proof. $\partial F_{h} / \partial \lambda \leq 0$ because $G$ is convex and $q_{0}$ is decreasing in $\lambda$, and direct computations show that $\partial F_{h} / \partial \lambda=\left(f_{h} / f_{l}\right) \partial F_{l} / \partial \lambda$.

Note that with such misclassification risk, the fact that condition (21) is binding $\left(\partial F_{h} / \partial \lambda=\left(f_{h} / f_{l}\right) \partial F_{l} / \partial \lambda\right)$ means that an increase in $\sigma$ does not yield a strict first-order increase in the informativeness of the signal. Unlike in the next example, the decrease in the cost of capital is only due to the fact that the cost of taking to market decreases.

\section{Idiosyncratic asset values}

Here we make two modifications to the model in Section 4.1. First, we suppose that the payoff of each firm's project is the sum of $h$ or $l$ and of an idiosyncratic component. This component is identically distributed across firms, and admits a log-concave density $\psi$ with full support over the real line. We denote by $\Psi$ its c.d.f.. Each firm (principal and agent) privately observes the realization of its own idiosyncratic risk at date 1 . So do matched buyers and thus bids are conditional on it.

Second, we now suppose that buyers are matched with firms at date $1^{33}$, at which a random subset of firms of each type experience a large private liquidity shock and need to sell their projects. For tractability, we make two simplifying assumptions. First, we suppose that the subset of firms experiencing a shock is negligible, so that these shocks do not affect ex-ante contracting and bidding decisions. Second, we preserve the information structure with univariate signals by assuming that each non-distressed firm can observe exactly one price from such a distressed transaction for a project of its own type.

\footnotetext{
${ }^{32}$ Given a bounded signal, we also need to assume that the likelihood ratio takes sufficiently extreme values in order to rule out equilibria with corner solutions whereby the signal is not used.

${ }^{33}$ This was immaterial thus far.
} 
If a distressed firm is not matched to any informed buyer, which occurs almost surely if it has a low-payoff project, or with probability $q_{0}$ it has a high-payoff one, then its project is sold at a price equal to the uninformed bid $\nu .{ }^{34}$ Otherwise it sells at the highest informed bid. The date-1 signal then has conditional c.d.f.:

$$
\begin{aligned}
& F_{l}(s)=\Psi(s-\nu), \\
& F_{h}(s)=\Psi *\left(H_{0}-q_{0}\right)(s)+q_{0} \Psi(s-\nu),
\end{aligned}
$$

where $*$ is the convolution operator and $H_{0}$ the distribution of the highest informed bid (with $\lim _{s \rightarrow-\infty} H_{0}(s)=q_{0}$ ). We also have that

$$
\frac{f_{h}(s)}{f_{l}(s)}=q_{0}+\left(1-q_{0}\right) \int \frac{\psi(s-t)}{\psi(s-\nu)} d H_{0}(t)
$$

is increasing in $s$ since $t \geq \nu$ on the support of $H_{0}$ in equilibrium.

Proposition 12. (Idiosyncratic project values) Under idiosyncratic project values, Proposition 10 applies and condition (21) holds strictly.

Proof. $F_{l}$ is not affected by $\lambda$ whereas $F_{h}$ strictly increases in the sense of first-order stochastic dominance as $\lambda$ increases since informed buyers compete more with each other and $\nu$ is constant.

It is interesting to relate these endogenous signals to the classification of assets or liabilities into levels 1, 2, or 3 by the International Financial Reporting Standards. A lower-level item is easier to measure on the basis of data from markets for comparable assets. Our model suggests that the level of an item is an endogenous object that depends on the degree of marking to market, and that laissez-faire yields excessively high levels.

\section{Conclusion}

This paper augments a standard agency-based model of corporate finance with a measurement friction. It offers a theory of optimal accounting measures in an environment in which both contractual relations between firms' stakeholders and liquidity in the market for firms' assets are the endogenous outcome of optimizing behaviors.

Gains trading arises naturally in the optimal contract as a substitute for relying on market data (marking to market). Their respective contributions to the provision of incentives have intuitive comparative statics properties.

Our main equilibrium result is that laissez-faire generically leads to a socially excessive degree of marking to market. When the liquidity of firms' assets is exogenously given,

\footnotetext{
${ }^{34}$ Uninformed bids are constant in the limiting case of infinite masses of uninformed buyers and lemons projects, an assumption that we adopt for simplicity.
} 
self-justified inefficient equilibria may arise whereby firms rely too much on market data of poor quality and sell their assets at excessively deep discounts following negative market signals. With endogenous asset liquidity, the equilibrium exhibits an excessive form of bootstrapping. It is inefficient because firms fail to internalize the negative liquidity externalities that they create for each other by contracting too much on transactions by other firms and too little on their own transactions. A lower degree of marking to market would enable firms to trade their assets at a lower cost, and would enhance the quality of market data.

There are many interesting routes for future research. For instance, firms' balance sheets are in practice comprised of very heterogeneous items. Consider for example the case of an insurance company with marketable assets backing complex and illiquid liabilities. We could formalize this in an extension in which firms run several "projects" for which market signals and resale options vary.

\section{References}

Acharya, V., De Marzo, P. and I. Kremer (2011) "Endogenous Information Flows and the Clustering of Announcements," American Economic Review, 101(7): 2955-79.

Admati, A. and P. Pfleiderer (1988) "A Theory of Intraday Patterns: Volume and Price Variability," Review of Financial Studies, 1(1): 3-40.

Aghion, P., Bolton, P. and J. Tirole (2004) "Exit Options in Corporate Finance: Liquidity versus Incentives," Review of Finance, 8: 327-353.

Allen, F. and E. Carletti (2008) "Mark-to-Market Accounting and Liquidity Pricing," Journal of Accounting and Economics, 45(2-3): 358-78.

Bleck, A. and P. Gao (2012), "Where does the Information in Mark-to-Market Come from?," mimeo, University of Chicago Booth School of Business.

Bleck, A. and X. Liu (2007), "Market Transparency and the Accounting Regime," Journal of Accounting Research, 45(2): 229-256.

Dye, R. (1986), "Optimal Monitoring Policies in Agencies," RAND Journal of Economics, 17(3): 339-350. 
Ellul, A., Jotikasthira, C., Lundblad, C. and Y. Wang (2015) "Is Historical Cost a Panacea? Market Stress, Incentive Distortions and Gains Trading," forthcoming, Journal of Finance.

Elyakime, B., Laffont, J.J., Loisel, P. and Q. Vuong (1994) "First-Price SealedBid Auctions with Secret Reservation Prices," Annales d'Economie et de Statistique, 34: 115-141.

Faure-Grimaud, A. and D. Gromb (2004) "Public Trading and Private Incentives," Review of Financial Studies, 17 (4): 985-1014.

Heaton, J., Lucas, D. and R. McDonald (2010) "Is Mark-to-Market Accounting Destabilizing? Analysis and Implications for Policy," Journal of Monetary Economics, 57: 64-75.

Holmström, B. (1979) "Moral Hazard and Observability," The Bell Journal of Economics, 10(1): 74-91.

Jehiel, P. and L. Lamy (2015a) "On the Use of Absolute Auctions and Secret Reserve Prices," forthcoming, Rand Journal of Economics.

Jehiel, P. and L. Lamy (2015b) "On Discrimination in Auctions with Endogenous Entry," American Economic Review, 105(8): 2595-2643.

Kim, S.K. (1995) "Efficiency of an Information System in an Agency Model," Econometrica, 63(1): 89-102.

Laux, C. and C. Leuz (2010) "Did Fair-Value Accounting Contribute to the Financial Crisis?," Journal of Economic Perspectives, 24(1): 93-118.

Levin, D. and J. L. Smith (1994) "Equilibrium in Auctions with Entry," American Economic Review, 84(3): 585-599.

Otto, C. and P. Volpin (2015) "Marking to Market and Inefficient Investment Decisions," mimeo, HEC Paris.

Pagano, M. (1989) "Endogenous Market Thinness and Stock Price Volatility," Review of Economic Studies, 56(2): 269-87. 
Plantin, G., Sapra, H. and H. Shin (2008) "Marking to Market: Panacea or Pandora's Box?," Journal of Accounting Research, 46(2): 435-460.

Townsend, R. (1979), "Optimal Contracts and Competitive Markets with Costly State Verification," Journal of Economic Theory, 21(2): 265-293. 


\section{Appendix}

\section{Proof of Proposition 1}

The revelation principle implies that we can restrict the analysis to direct mechanisms in which the agent has incentives to report according to its type. Let us denote by $u_{y}(s)$ the expected utility that such a mechanism grants to the agent when the signal is $s$ and the cash flow is $y \in\{l ; h\}$. We also denote $x_{y}(s)$ the probability to sell the asset conditionally on a signal $s$ and on a report $y$. Finally, $v_{y}(s)$ is the utility provided to the agent if there is no asset sale, and $w_{y}(s)$ that following a sale. For such mechanisms, the optimal contract solves

$$
\min \left\{\int\left[p f_{h}(s)\left[u_{h}(s)+c_{h} x_{h}(s)\right]+(1-p) f_{l}(s)\left[u_{l}(s)+c_{l} x_{l}(s)\right]\right] d s\right\}
$$

s.t.

$$
\begin{aligned}
& 0 \leq u_{y}(s)=\left[1-x_{y}(s)\right] v_{y}(s)+x_{y}(s) w_{y}(s) \leq 1 \text { for } y \in\{h, l\} \\
& {\left[1-x_{h}(s)\right] v_{h}(s) \leq u_{l}(s)} \\
& {\left[1-x_{l}(s)\right] v_{l}(s) \leq u_{h}(s)} \\
& \quad \int\left[f_{h}(s) u_{h}(s)-f_{l}(s) u_{l}(s)\right] d s \geq \beta
\end{aligned}
$$

The objective (28) is to minimize the sum of two types of costs: the expected cost of providing utility $u_{y}(s)$ to the agent and the expected transaction costs corresponding to the costs $c_{h}, c_{l}$. Relations (30) and (31) are ex-post incentive-compatibility constraints imposing that the agent finds it optimal to report the true cash flow. Notice that (30) and (31) directly assume that if the agent is caught lying because the sale price does not correspond to his report, then he receives the minimum utility 0 , which is obviously optimal. Finally, condition (32) is the ex-ante incentive-compatibility constraint ensuring that the agent finds it optimal to behave at date 0 .

Note first that any optimal contract must be such that condition (30) is binding with

$$
\begin{aligned}
& x_{l}(s)=0, \\
& u_{l}(s)=v_{l}(s)=\left[1-x_{h}(s)\right] v_{h}(s) .
\end{aligned}
$$

This both reduces the total cost (28) and creates larger incentives to behave. Taking into account (33) and (34), and the fact that the incentive-compatibility constraint (32) is also optimally binding (otherwise one can just scale down all payments), the program defining the optimal mechanism simplifies into: 


$$
\min \left\{p \beta+\int\left[f_{l}(s) v_{l}(s)+p f_{h}(s) c_{h}\left(x_{h}(s), s\right)\right] d s\right\}
$$

s.t.

$$
\begin{aligned}
& \int\left[\left[f_{h}(s)-f_{l}(s)\right] v_{l}(s)+f_{h}(s) x_{h}(s)\right] d s=\beta, \\
& {\left[1-x_{h}(s)\right] v_{h}(s)=v_{l}(s) .}
\end{aligned}
$$

This formulation also takes into account that it is optimal that the agent receives 1 whenever a sale reveals a high cash flow $\left(w_{h}(s)=1\right)$. This yields a Lagrangian

$$
\mathfrak{L}\left(v_{h}(.), x_{h}(.), \alpha\right)=\int\left[\begin{array}{l}
{\left[\alpha\left[f_{h}(s)-f_{l}(s)\right]-f_{l}(s)\right]\left[1-x_{h}(s)\right] v_{h}(s)} \\
+\left[\alpha-p c_{h}\right] f_{h}(s) x_{h}(s)
\end{array}\right] d s-\alpha \beta,
$$

where $\alpha$ is the shadow price of (36). Pointwise optimization yields $v_{h}(s)=1_{\{s \geq \sigma\}}$, where $p c_{h} L(\sigma)=1$, and $x_{h}(s)=0$ for $s \geq \sigma$.

Finally, the expression of the cost of capital (2) stems directly from computing the objective (35) under the optimal contract.

\section{Proof of Proposition 3}

In case of a date- 2 resale, the price reveals the project's payoff, and thus the principal knows it at date 3. If the firm holds on to the asset until date 3 , the payoff is revealed at this date. This implies that either way, the principal knows the payoff at date 3 . The information conveyed by the date- 1 signal and date- 2 actions is thus immaterial at this date. Also, the cost of providing utility at date 3 is independent of any utility already provided at date 2 . Thus, one can without loss of generality consider only contracts whereby the date-3 compensation does not depend on the contracting history, only on the realized payoff. Denote $(\sigma, x, y)$ such a contract. It is such that the agent is rewarded at date 2 if the signal is above $\sigma$, or with probability $x$ if it is below $\sigma$ and he manages to sell the project at a high price. He may also be rewarded at date 3 with probability $y$ if the project pays off $h$. An optimal contracts solves the counterpart of $\{(3),(4)\}$

$$
\min _{\{\sigma, x, y\}}\left\{1-F_{l}(\sigma)+p F_{h}(\sigma) c_{h} x+p(1-\delta) y\right\}
$$

s.t.

$$
F_{l}(\sigma)-F_{h}(\sigma)+x F_{h}(\sigma)+\delta y=\beta
$$

Linearity in $x, y$ implies that if $\delta\left(1+c_{h}\right) \leq 1$, then $y=0$ is optimal and the problem is that solved in Proposition 1. If $\delta\left(1+c_{h}\right)>1$, then ignoring feasibility constraints in $x, y$ 
yields an optimal contract $(\widehat{\widehat{\sigma}}, x, y)$ defined as:

$$
\begin{aligned}
& x=0, \\
& L(\widehat{\widehat{\sigma}})=\frac{\delta}{p(1-\delta)}, \\
& F_{l}(\widehat{\widehat{\sigma}})-F_{h}(\widehat{\widehat{\sigma}})+\delta y=\beta .
\end{aligned}
$$

If $F_{l}(\widehat{\widehat{\sigma}})-F_{h}(\widehat{\widehat{\sigma}})>\beta$ then $x=y=0$ and the signal cut-off is above $\widehat{\widehat{\sigma}}$. If $F_{l}(\widehat{\widehat{\sigma}})-F_{h}(\widehat{\widehat{\sigma}})+\delta<$ $\beta$ then $y=1$ and $\sigma$ and $x$ solve the same problem as in Proposition 1 with $\beta^{\prime}=\beta-\delta$.

\section{Proof of Lemma 5}

We first show that bidding strategies are either degenerate or must have a continuous c.d.f. If a bidding strategy has $h$ in its support then it must be a Dirac delta at $h$ since bidders must be indifferent between all bids. Suppose a bidding strategy is nondegenerate. We show that it cannot have an atom at any point of its support. Suppose otherwise that it is not left-continuous at some point of the support (necessarily strictly smaller than $h$ ). Then bids in the right-neighborhood of this point strictly dominate a bid at this point, which cannot be.

The fact that bids must have a continuous c.d.f. implies that the contracts set by firms are given by Proposition 4 .

We then show that the lower bound of the support of $S, r_{0}$, is equal to the reservation price $r$ anticipated by bidders. It must be that $r_{0} \geq r$. Suppose $r_{0}>r$. We know from the above that $S$ is atomless at $r_{0}$. This implies that bidding $r$ strictly dominates bidding $r_{0}$, which cannot be. Thus $r=r_{0}$.

We then compute $\pi_{2}$, the expected profit of an informed buyer. We have just seen that the distribution of bids $S$ is atomless with support of the form $\left[r, r_{+}\right] \subset[r, h]$. Thus the expected profit $\pi_{2}$ of a bidder satisfies:

$$
\text { For all } t \in\left[r, r_{+}\right], F_{h}(\sigma) \sum_{k \geq 1} \frac{q_{k}}{1-q_{0}}(h-t) S^{k-1}(t)=\pi_{2}
$$

which for $t=r$ yields

$$
\pi_{2}=\frac{F_{h}(\sigma) q_{1}(h-r)}{1-q_{0}} .
$$

This implies that the expected selling cost for a firm is

$$
p \frac{\lambda}{p} \pi_{2}=F_{h}(\sigma) \frac{\lambda q_{1}(h-r)}{1-q_{0}} .
$$


The incentive-compatibility constraint (20) is derived in the body of the paper, and the first-order condition (19) stems from

$$
\begin{aligned}
& \frac{f_{h}(\sigma)}{f_{l}(\sigma)}=\frac{p(h-r)+1}{p(h-r) H(r)+p \int_{r}^{h}(h-t) d H(t)}, \\
& H(r)=q_{0}, \\
& p \int_{r}^{h}(h-t) d H(t)=\frac{\lambda q_{1}(h-r)}{1-q_{0}} .
\end{aligned}
$$

Finally, note that, using the incentive-compatibility constraint, the cost of capital can be re-written as

$$
1-\beta+p \beta+F_{h}(\sigma)\left[\frac{\lambda q_{1}(h-r)}{1-q_{0}}-q_{0}\right] .
$$

The term in square brackets is positive (negative) if $f_{h} q_{0} / f_{l}<1\left(f_{h} q_{0} / f_{l}>1\right)$.

\section{Proof of Proposition 7}

It is easy to see that an optimal $\sigma^{\prime}$-contract consists in rewarding the agent based on a signal larger than $\sigma^{R} \geq \sigma^{\prime}$ and allowing him to sell the asset above some reserve price otherwise, where $\sigma^{R}$ may be infinite. That the incentive-compatibility constraint must be binding, and that the equilibrium probability of resale is $q_{0}$ whenever resale is allowed, imply that for every $\sigma^{\prime} \in(\underline{\sigma}, \bar{\sigma}]$, the only equilibrium with $\sigma^{\prime}$-contracts is the one with the contract $(\bar{\sigma}, \bar{r})$. If $\sigma^{\prime}>\bar{\sigma}$, there is no equilibrium with incentive-compatible $\sigma^{\prime}$-contracts.

\section{Proof of Proposition 8}

We skip the proof that an equilibrium contract must be of the form $(\sigma(\lambda), r(\lambda))$. Such a contract solves

$$
\begin{aligned}
& \max _{(\sigma(.), r(.))}\left\{\int\left[1-F_{l}(\sigma(\lambda))+p F_{h}(\sigma(\lambda)) \int_{r(\lambda)}^{h}(h-t) \frac{\partial H(t, \lambda)}{\partial t} d t\right] d \Lambda(\lambda)\right\} \\
& \text { s.t. } \\
& \int\left[F_{l}(\sigma(\lambda))-H(r(\lambda), \lambda) F_{h}(\sigma(\lambda))\right] d \Lambda(\lambda)=\beta
\end{aligned}
$$

The first-order condition yields

$$
\begin{aligned}
& r(\lambda)=r, \\
& \frac{f_{h}(\sigma(\lambda))}{f_{l}(\sigma(\lambda))}=\frac{p(h-r)+1}{p \int_{r}^{h}(h-t) H(t, \lambda) d t} .
\end{aligned}
$$


It only remains to show that $H(t, \lambda)$ increases in $\lambda$ in the sense of first-order stochastic dominance $(\partial H / \partial \lambda \leq 0)$. Note first that the distribution of bids $S(., \lambda)$ satisfies

$$
\sum_{k \geq 1} \frac{q_{k}(\lambda)}{q_{1}(\lambda)}(h-t) S^{k-1}(t, \lambda)=h-r .
$$

That $q_{k} / q_{1}$ increases in $\lambda$ implies that $S(t, \lambda)$ must decrease w.r.t. $\lambda$ for all $t$. Second,

$$
H=\sum_{k \geq 0} q_{k} S^{k}
$$

implies that so does $H$ from first-order stochastic dominance.

\section{Proof of Proposition 9}

For $\epsilon$ sufficiently small, for each $\lambda$ such that $\left(1-q_{0}(\lambda)\right) \in[\beta-\epsilon, \beta)$, there exists a unique $\sigma$ such that (23) holds and $f_{h} q_{0} / f_{l}>1$ for $(\lambda, \sigma)$. Continuity implies that the set of $\sigma$ defined this way is an interval $\left[\sigma_{1},+\infty\right)$. Further, differentiating the incentive-compatibility $(23)$ constraint yields:

$$
\frac{\partial \sigma}{\partial \lambda}=\frac{\frac{\partial q_{0}}{\partial \lambda} F_{h}+q_{0} \frac{\partial F_{h}}{\partial \lambda}-\frac{\partial F_{l}}{\partial \lambda}}{f_{l}-q_{0} f_{h}}>0
$$

because

$$
q_{0} \frac{\partial F_{h}}{\partial \lambda}-\frac{\partial F_{l}}{\partial \lambda} \leq \frac{\partial F_{h}}{\partial \lambda}\left(q_{0}-\frac{f_{l}}{f_{h}}\right) \leq 0
$$

from condition (21).

For any $\sigma \geq \sigma_{1}$, one can then uniquely define $\lambda(\sigma)$ and $r(\sigma)$ such that (23) and (24) are satisfied for $(\sigma, r(\sigma), \lambda(\sigma))$. Define then $\Sigma(\sigma)$ as the solution to $(22)$ for such $(r(\sigma), \lambda(\sigma))$. For $\kappa$ sufficiently small, $r(\sigma)$ takes values in a compact set that is sufficiently close to $h$ and thus $\Sigma(\sigma) \geq \sigma_{1}$ for all $\sigma \geq \sigma_{1}$. Also, $\Sigma$ is bounded from above because $\lambda(\sigma)$ and $r(\sigma)$ take values in compact sets. Denoting $\sigma_{2}$ this upper bound, $\Sigma$ is an (obviously continuous) mapping over $\left[\sigma_{1}, \sigma_{2}\right]$ and thus admits a fixed point which is a stable equilibrium by construction.

\section{Proof of Proposition 10}

Note first that the equilibrium distribution of the highest bid is given by:

$$
\begin{aligned}
& \sum_{k \geq 1} \frac{q_{k}(\lambda)}{q_{1}(\lambda)}(h-t) S^{k-1}(t)=h-r, \\
& H=\sum_{k \geq 0} q_{k} S^{k} .
\end{aligned}
$$


This implies that this distribution $H$ is fully determined by the equilibrium values of $\lambda$ and $r$, and that $H(., \lambda, r)$ increases in $\lambda$ and $r$ in the sense of first-order stochastic dominance. (The argument is identical to that in the proof of Proposition 8).

Second, taking $\lambda, \sigma$ and $r$ as given, an individual firm chooses a contract $\left(\sigma^{\prime}, r^{\prime}\right)$ that solves:

$$
\max _{\left(\sigma^{\prime}, r^{\prime}\right)} V\left(\sigma^{\prime}, r^{\prime}\right)=F_{l}\left(\sigma^{\prime}, \lambda\right)-p F_{h}\left(\sigma^{\prime}, \lambda\right) \int_{r^{\prime}}^{h}(h-t) \frac{\partial H(t, \lambda, r)}{\partial t} d t
$$

s.t.

$$
F_{l}\left(\sigma^{\prime}, \lambda\right)-F_{h}\left(\sigma^{\prime}, \lambda\right) H\left(r^{\prime}, \lambda, r\right)=\beta
$$

The Lagrangian of this program is

$$
\begin{aligned}
\mathfrak{L} & =V\left(\sigma^{\prime}, r^{\prime}\right)+p\left(h-r^{\prime}\right)\left[F_{l}\left(\sigma^{\prime}, \lambda\right)-F_{h}\left(\sigma^{\prime}, \lambda\right) H\left(r^{\prime}, \lambda, r\right)-\beta\right] \\
& =\left[1+p\left(h-r^{\prime}\right)\right] F_{l}\left(\sigma^{\prime}, \lambda\right)-F_{h}\left(\sigma^{\prime}, \lambda\right)\left[p \int_{r^{\prime}}^{h} H(t, \lambda, r) d t\right]-\beta p\left(h-r^{\prime}\right) .
\end{aligned}
$$

The envelope theorem then yields that at the equilibrium values $\left(\sigma^{\prime}, r^{\prime}\right)=(\sigma, r)$,

$$
\begin{aligned}
\frac{\partial V}{\partial \lambda} & =\left[[1+p(h-r)] \frac{\partial F_{l}(\sigma, \lambda)}{\partial \lambda}-\frac{\partial F_{h}(\sigma, \lambda)}{\partial \lambda}\left[p \int_{r}^{h} H(t, \lambda, r) d t\right]\right] \\
& -p F_{h}(\sigma, \lambda) \int_{r}^{h} \frac{\partial H(t, \lambda, r)}{\partial \lambda} d t \\
\frac{\partial V}{\partial r} & =-p F_{h}(\sigma, \lambda) \int_{r}^{h} \frac{\partial H(t, \lambda, r)}{\partial r} d t .
\end{aligned}
$$

Conditions (21) and (22) imply that

$$
[1+p(h-r)] \frac{\partial F_{l}(\sigma, \lambda)}{\partial \lambda}-\frac{\partial F_{h}(\sigma, \lambda)}{\partial \lambda}\left[p \int_{r}^{h} H(t, \lambda, r) d t\right]
$$

is positive in equilibrium. Thus an increase in $\lambda$ yields more efficient equilibrium contracting through a lower cost of marking to market, strictly so if (21) is strict. Even when (21) binds, an increase in $\lambda$ improves contracting because it reduces the cost of taking to market by inducing more aggressive bidding (term $-p F_{h}(\sigma, \lambda) \int_{r}^{h} \partial H(t, \lambda, r) / \partial \lambda d t$ ), and so does an increase in the reserve price $r\left(\right.$ term $\left.-p F_{h}(\sigma, \lambda) \int_{r}^{h} \partial H(t, \lambda, r) / \partial r d t\right)$.

Suppose now that the planner forces a contract with cut-off $\sigma^{\prime}>\sigma$. An incentivecompatible equilibrium must be such that firms reward their agents if the signal is above $\sigma^{\prime}$ and use otherwise a reserve price $r^{\prime}$ that leads to a speculative activity $\lambda^{\prime}$ such that (23) and (24) hold given $\sigma^{\prime}$ :

$$
\begin{aligned}
& F_{l}\left(\sigma^{\prime}, \lambda^{\prime}\right)-F_{h}\left(\sigma^{\prime}, \lambda^{\prime}\right) q_{0}\left(\lambda^{\prime}\right)=\beta, \\
& F_{h}\left(\sigma^{\prime}, \lambda^{\prime}\right) \frac{q_{1}\left(\lambda^{\prime}\right)\left(h-r^{\prime}\right)}{1-q_{0}\left(\lambda^{\prime}\right)}=\kappa .
\end{aligned}
$$


By continuity there exists such a triplet $\left(\sigma^{\prime}, r^{\prime}, \lambda^{\prime}\right)$ provided $\sigma^{\prime}$ is sufficiently close to $\sigma$. It only remains to show that $r^{\prime}>r$ and $\lambda^{\prime}>\lambda$. The latter result we already established in the proof of Proposition 9 where we showed that (23) implicitly defines a strictly increasing $\lambda(\sigma)$. Rewriting (24) as:

$$
\left[F_{l}(\sigma, \lambda)-\beta\right] \frac{q_{1}(\lambda)(h-r)}{q_{0}(\lambda)\left(1-q_{0}(\lambda)\right)}=\kappa
$$

shows that an increase in $\sigma$ also yields an increase in $r$ since $q_{1} / q_{0}\left(1-q_{0}\right)$ increases in $\lambda$, and (23) and condition (21) imply:

$$
f_{l}+\frac{\partial F_{l}}{\partial \lambda} \frac{\partial \lambda}{\partial \sigma} \geq \frac{\partial \lambda}{\partial \sigma} \frac{\frac{\partial q_{0}}{\partial \lambda} F_{h}}{\left(1-\frac{q_{0} f_{h}}{f_{l}}\right)}>0 .
$$



and Political Science Houghton Street London WC2A 2AE United Kingdom

Tel: +44 (0)207405 7686 systemicrisk.ac.uk src@Ise.ac.uk 